

ORNL/TM-8366



MASTER

RIDGE

NATIONAL

LABORATORY

UNION

CARBIDE

\title{
Simultaneous Heat and Mass Transfer in Absorption of Gases in Laminar Liquid Films
}

Gershon Grossman



OPERATED BY

UNION CARBIDE CORPORATION

FOR THE UNITED STATES

DEPARTMENT OF ENERGY 


\section{DISCLAIMER}

This report was prepared as an account of work sponsored by an agency of the United States Government. Neither the United States Government nor any agency Thereof, nor any of their employees, makes any warranty, express or implied, or assumes any legal liability or responsibility for the accuracy, completeness, or usefulness of any information, apparatus, product, or process disclosed, or represents that its use would not infringe privately owned rights. Reference herein to any specific commercial product, process, or service by trade name, trademark, manufacturer, or otherwise does not necessarily constitute or imply its endorsement, recommendation, or favoring by the United States Government or any agency thereof. The views and opinions of authors expressed herein do not necessarily state or reflect those of the United States Government or any agency thereof. 


\section{DISCLAIMER}

Portions of this document may be illegible in electronic image products. Images are produced from the best available original document. 


\section{Printed in the United States of America. Avallable from National Technical Information Service \\ U.S. Department of Commerce \\ 5285 Port Royal Road, Springfield, Virginia 22161 \\ NTIS price codes-Printed Copy: A05; Microfiche A01}

This report was prepared as an account of work sponsored by an agency of the United States Government. Neither the United States Government nor any agency thereof, nor any of their employees, makes any warranty, express or implied, or assumes any legal liability or responsibility for the accuracy, completeness, or usefulness of any information, apparatus, product, or prociess disclused, ur represents that its use would not infringe privately owned rights. Reference herein to any specific commercial product, process, or service by trade name, trademark, manufacturer, or otherwise, does not necessarily constitute or imply its endorsement, recommendation, or favoring by the United States Government or any agency thereof. The views and opinions of authors expressed herein do not necessarily state or reflect those of the United States Government or any agency thereof. 
SIMULTANEOUS HEAT AND MASS TRANSFER IN .

ABSORPTION OF GASES IN LAMINAR LIQUID FILMS

Gershon Grossman

Date Published - September 1982

Contract No. W-7405-eng-26

Oak Ridge National Laboratory Oak Ridge, Tennessee 37830 operated by

Union Carbide Corporation for the

Department of Energy

This report was prepared as an account of work sponsored by an agency of the United States Government. Neither the United States Government nor any agency thaseot, nor any of their employees, makes any warranty. express or implied, or assumes any legal liability or responsibility for the eccuracy. completeness. or usefulness of any information, apparatus. product. or process disclosed, or represents that its use would not infringe privately owned rights. Reterence herein to any specitic




THIS PAGE

\section{WAS INTENTIONALLY LEFT BLANK}


CONTENTS

LIST OF FIGURES . • . . . . . . . . . . . . . . . . . v

LIST OF TABLES. . . . . . . . . . . . . . . . . . vii

NOMENCLATURE. . . . . . . . . . . . . . . . . . . ix

ABSTRACT. . . . . . . . . . . . . . . . . . xii xi

EXECUTIVE SUMMARY . . . . . . . . . . . . . . . . . . xv

1. INTRODUCTION. . . . . . . . . . . . . . . . . 1

2. MODEL AND EQUATIONS . . . . . . . . . . . . . . . 5

3. THE LINEAR ABSORBENT. . . . . . . . . . . . . . . 11

4. EXACT SOLUTION. . . . . . . . . . . . . . . . 15

5. RESUlTS AND DISCUSSION. . . . . . . . . . . . . 25

6. HEAT AND MASS TRANSFER COEFFICIENTS . . . . . . . . . 33

7. INTEGRAL SOlUTion . . . . . . . . . . . . . . 37

8. NUMERICAL EXAMPLE . . . . . . . . . . . . . . 55

9. CONCLUSIONS ..................... 61

REFERENCES. . . . . . . . . . . ........ 63

ACKNOWLEDGMENTS . . . . . . . . . . . . . . . 65 


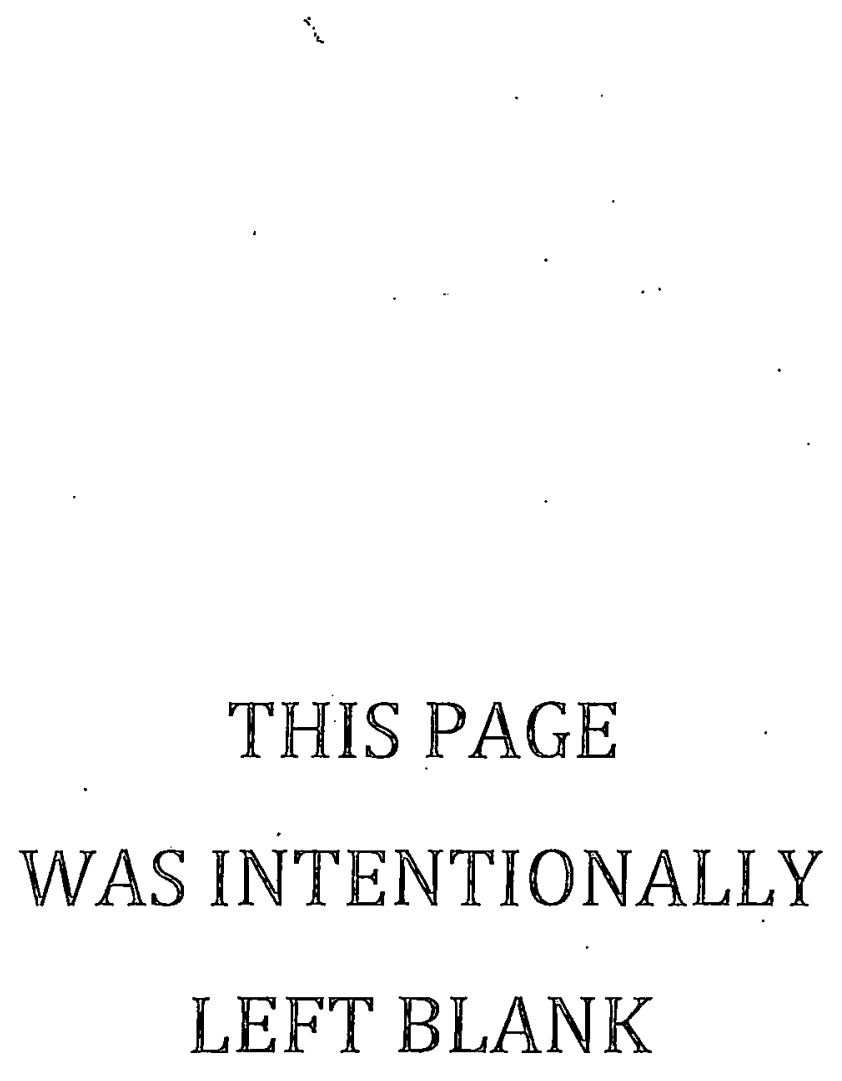


LIST OF FIGURES

1. Description of falling film of absorbent in contact with absorbate . . . . . . . . . . . . . . . . . . 5

2. Dimensionless wall; liquid bulk, and interface temperatures as functions of the normalized length $\zeta$ for Le $=0.001$ and

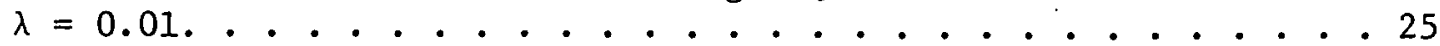

3. Dimensionless wall, liquid bulk, and interface concentrations as functions of the normalized length $\zeta$ for Le $=0.001$ and

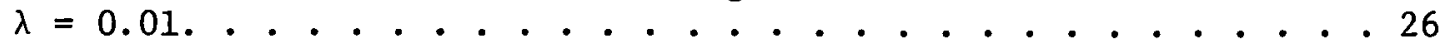

4. Typical profiles of dimensionless temperature and concentration across the film at different values of $\zeta$ for adiabatic wall where Le $=0.001$ and $\lambda=0.01$. . . . . . . . . . 27

5. Typical profiles of dimensionless temperature and concentration across the film at different values of $\zeta$ for constanttemperature wall where $\mathrm{Le}=0.001$ and $\lambda=0.01 . . . . . .28$

6. Dimensionless interface temperature and concentration as functions of the normalized length $\zeta$ for Le $=0.001$ and



7. Dimensionless wall temperature and concentration as functions of the normalized length $\zeta$ for $\mathrm{Le}=0.001$ and different values

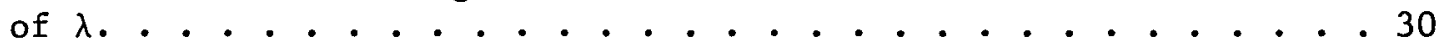

8. Dimensionless interface temperature and concentration as functions of the normalized length $\zeta$ for $\lambda=0.01$ and different values of Le. . . . . . . . . . . . . . . . . . . 31

9. Dimensionless wall temperature and concentration as functions of the normalized length $\zeta$ for $\lambda=0.01$ and different values of Le........................ . . 31

10. Dimensionless mass $f l u x$ at the interface as a function of the normalized length $\zeta$ for Le $=0.001$ and different values of $\lambda$. . 32

11. Local Sherwood number as a function of the normalized length $\zeta$ for different values of le and $\lambda . . . . . . . . . . .34$

12. Local Nusse1t number as a function of the normalized length $\zeta . .35$

13. Qualitative distribution of the temperature and concentration in the falling film: (a) adiabatic wall and (b) constanttemperature wall. . . . . . . . . . . . . . . . 38 
14. Main dimensicnless system parameters as functions of the normalized length $\zeta$ for Le $=0.001$ and $\lambda=0.01$ : (a) boundary layer thicknesses, (b) temperatures, (c) concentrations, and (d) heat and mass fluxes................... . . 52

15. Thermodynamic equilibrium chart for $\mathrm{LiBr}-\mathrm{H}_{2} \mathrm{O}$ solution illustrating the absorption process with an adiabatic wall and a constant-temperature wall, under the conditions of the numerical example. . . 56 


\section{LIST OF TABLES}

1. Eigenvalues and coefficients for typical values of the parameters ....................... 18

2. Physical properties of $\mathrm{LiBr}-\mathrm{H}_{2} \mathrm{O}$ solution at $60 \%$ concentration and $75^{\circ} \mathrm{C}$. . . . . . . . . . . . . . 57 


\section{THIS PAGE}

\section{WAS INTENTIONALLY \\ LEFT BLANK}




$$
\begin{aligned}
& \mathrm{C} \quad-\text { concentration of absorbate in solution }\left(\frac{\text { moles }}{\mathrm{m}^{3} \text { solution }}\right) \\
& \mathrm{C}_{\mathrm{e}} \text { - equilibrium concentration of solution at temperature } \mathrm{T}_{\mathrm{o}} \\
& \text { with vapor at pressure } \mathrm{P}_{\mathrm{v}}\left(\frac{\text { moles }}{\mathrm{m}^{3} \text { solution }}\right) \\
& c_{i} \quad-\quad \text { interfacial concentration of absorbate in solution }\left(\frac{\text { moles }}{\mathrm{m}^{3} \text { solution }}\right) \\
& \mathrm{C}_{0} \quad \text { initial concentration of absorbate in solution }\left(\frac{\text { moles }}{\mathrm{m}^{3} \text { solution }}\right) \\
& \mathrm{C}_{1}, \mathrm{C}_{2}-\text { constants, Eq. (17a) } \\
& \overline{\mathrm{C}} \quad-\text { bulk concentration of absorbate in solution }\left(\frac{\text { moles }}{\mathrm{m}^{3} \text { solution }}\right) \\
& c_{p}-\text { specific heat of liquid }\left(\mathrm{J} / \mathrm{kg} \cdot{ }^{\circ} \mathrm{C}\right) \\
& \text { D - diffusion coefficient of absorbate (substance II) in solution } \\
& \left(\mathrm{m}^{2} / \mathrm{s}\right) \\
& \overline{\mathrm{H}}_{\mathrm{a}} \quad-\text { heat of absorption of substance II in solution ( } \mathrm{J} / \mathrm{mole} \text { ) } \\
& \overline{\mathrm{H}}_{\mathrm{II}}-\text { partial molal enthalpy of substance II at interface ( } \mathrm{J} / \mathrm{mole} \text { ) } \\
& h_{f g o}-\text { latent heat of. evaporation at temperature } T_{0}(\mathrm{~J} / \mathrm{kg}) \\
& h_{M}-\text { mass transfer coefficient from interface to bulk (m/s) } \\
& h_{\mathrm{T}} \quad-\text { heat transfer coefficient from interface to bulk }\left(\mathrm{W} / \mathrm{m}^{2} \cdot{ }^{\circ} \mathrm{C}\right) \\
& \left.\mathrm{h}_{\mathrm{T}}{ }^{\prime}-\text { heat transfer coefficient from bulk to wall (W/m } 2 \cdot{ }^{\circ} \mathrm{C}\right) \\
& \overline{\mathrm{h}}_{\mathrm{II}} \text { - enthalpy of vapor in contact with film (J/mole) }
\end{aligned}
$$




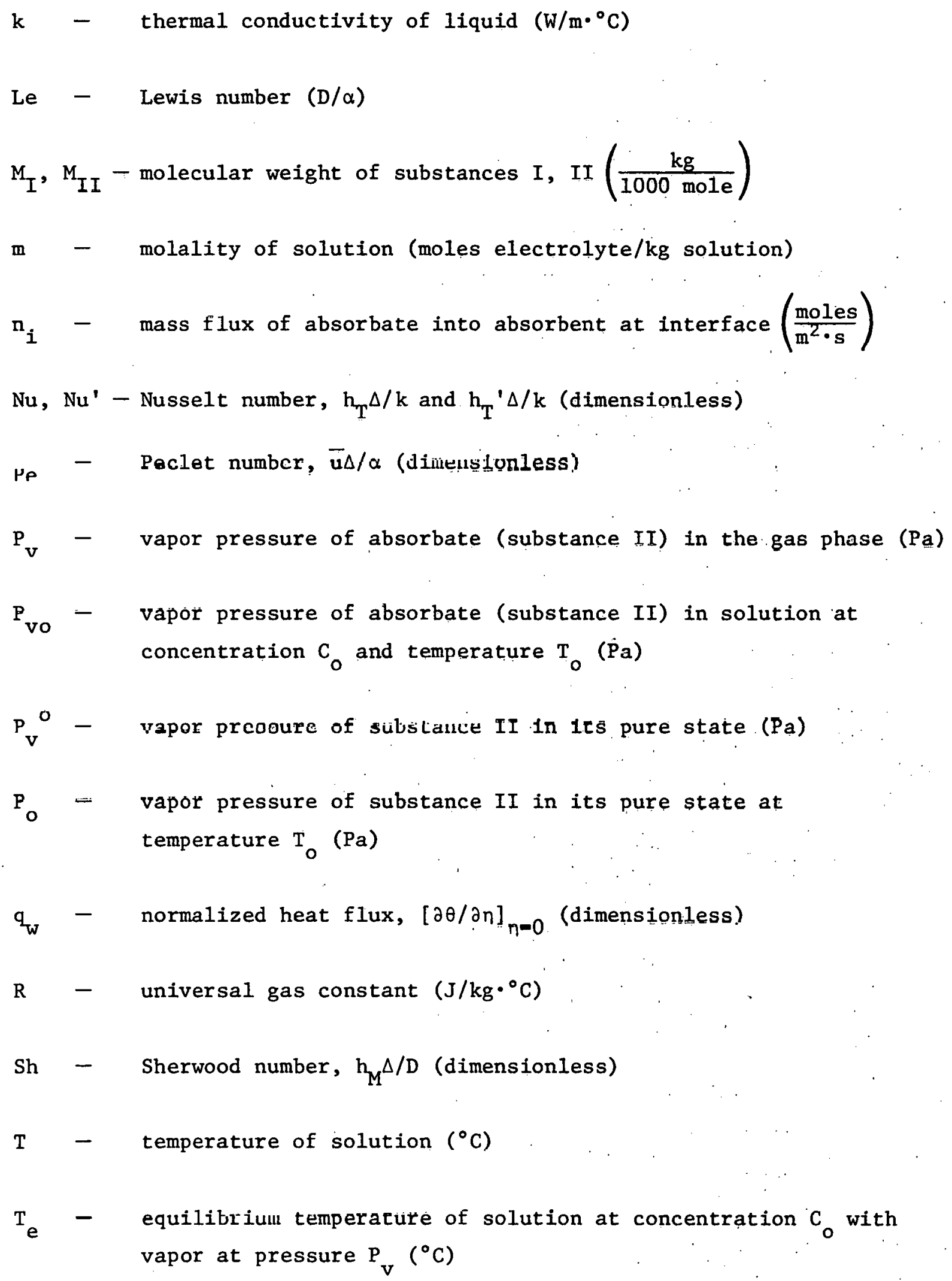














\section{SIMULTANEOUS HEAT AND MASS TRANSFER IN \\ ABSORPTION OF GASES IN LAMINAR LIQUID FILMS}

\section{ABSTRACT}

This report describes a theoretical analysis of the combined heat and mass transfer process taking place in the absorption of a gas or vapor into a laminar liquid film. This type of process, which occurs in many gas-liquid systems, often releases only a small amount of heat, making the process almost isothermal. In some cases, however, the heat of absorption is significant and temperature variations cannot be ignored. One example, from which the present study originated, is in absorption heat pumps where mass transfer is produced spectfically to generate a temperature change.

The model analyzed in this study describes a liquid film that flows over an inclined plane and has its free surface in contact with stagnant vapor. The absorption 'process at the surface creates nonuniform temperature and concentration profiles in the film, which develop until equilibrium between the liquid and vapor is achieved. The energy and diffusion equations are solved simultaneously to give the temperature and concentration variations at the interface and the wall. Two cases of interest. are considered: constant-temperature and adiabatic walls. The Nusselt and Sherwood numbers are expressed in terms of the operating parameters, from which heat and mass transfer coefficients can be determined. The Nusselt and Sherwood numbers are found to depend on the Peclet and Lewis numbers as well as on the equilibrium characteristics of the working materials. 


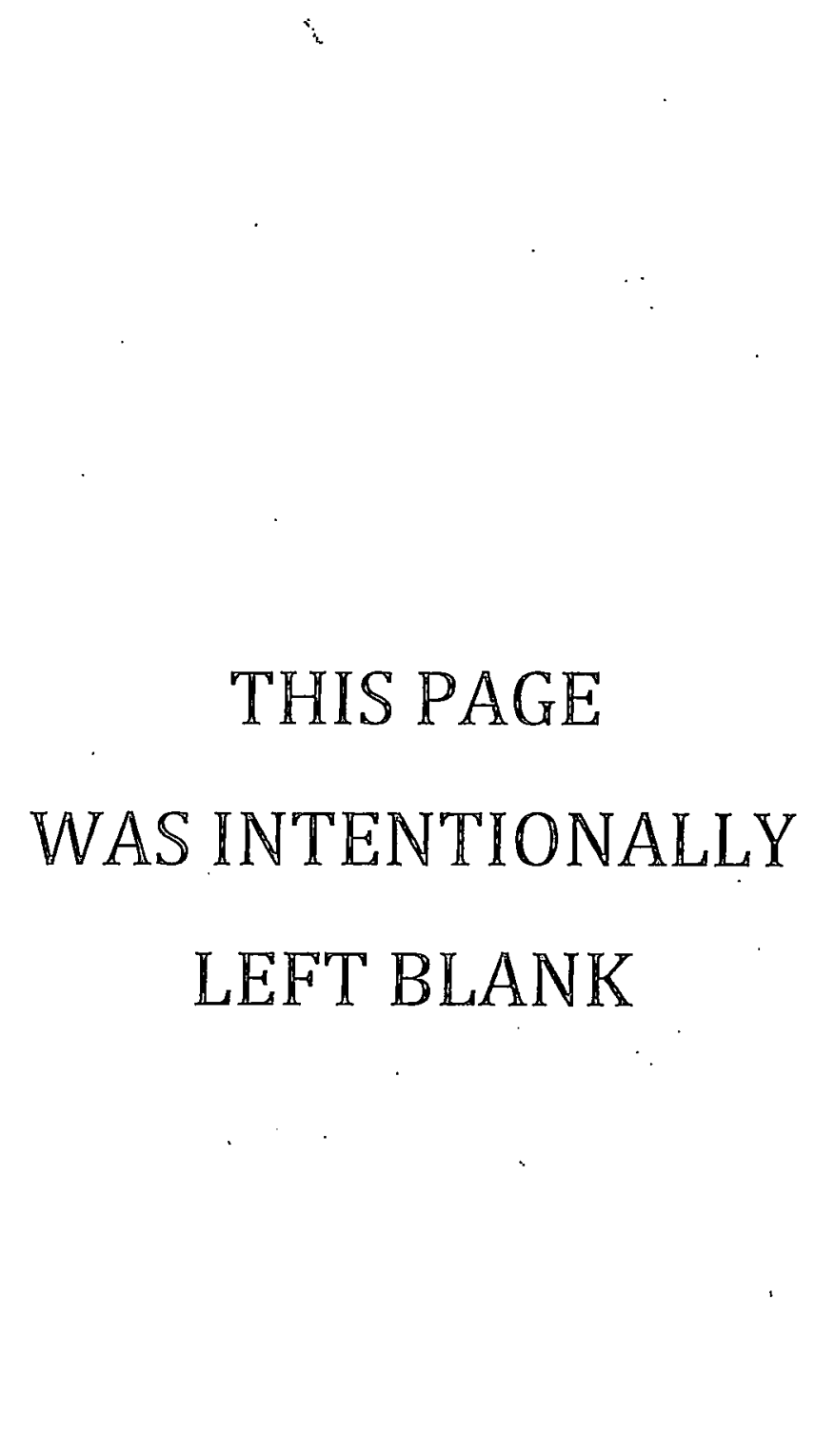


This report describes the approach to theoretical analysis of the combined heat and mass transfer process taking place in absorption systems. The two transfer phenomena are strongly coupled in these systems. The purpose of the analysis is to relate, quantitatively, the heat and mass transfer coefficients to the physical properties of the working fluids and to the geometry of the system. The preferred configuration is that of a falling film of liquid on a metallic surface which transfers heat from the absorbent in contact with the vapor of the absorbate.

This study originated'from ORNL's program on absorption heat pumps. In trying to optimize the design of absorbers and desorbers for these systems, it was recognized that fundamental, quantitative information on the combined heat and mass transfer process was lacking. Correlations of an empirical nature (not always publicly available) exist for determining the transfer coefficients for specific fluid pairs in specific geometries. Theoretical models backed by experimental data exist on gas absorption in liquid films, but they deal only with isothermal mass transfer and neglect the effect of heat transfer. The aim of the present study has been to produce the kind of fundamental understanding ful the combinen process that is already available for pure heat transfer or pure mass transfer. A theoretical analysis is the first step in this direction. Our model calculates the temperature and concentration distributions in the fllus and the resulting transfer coefficients for typical flow regimes, geometries, and boundary conditions. One of the important results of the analysis is the scaling laws of the system.

In the system analyzed, a film of liquid solution, composed of substances I (absorbent) and II (absorbate), flows down over an inclined plane. The film is in contact with stagnant vapor of substance II at constant pressure $\mathrm{P}_{\mathrm{v}}$. At $\mathrm{x}=0$, the liquid solution is at a uniform temperature $T_{0}$ and composition $C_{0}$ (moles of substance II per unit of volume of solution) corresponding to an equilibrium vapor pressure $P_{\text {vo }}$ lower than $\mathrm{P}_{\mathrm{V}}$. As a result of this difference, absorption takes place 
at the liquid-vapor interface. The substance absorbed diffuses into the film, and the heat generated in the absorption results in a simultaneous heat transfer process. Two cases of practical interest are considered: in one, the wall is kept at a constant temperature $\mathrm{T}_{0}$; in the other, the wall is adiabatic.

In formulating the model, the following assumptions have been made:

1. The liquid solution's properties are constant and independent of temperature and concentration.

2. The mass of vapor absorbed is small compared with the maor flow rate of the liquid. Therefore, the latter is constant and so is the film thickness.

3. There is no heat transfer in the vapor phase.

4. Therc are uU narural convection effects in the film due to temperature or concentration differences.

5. Diffusion thermal effecto are lieg11gible.

6. Vapor pressure equilibrium exists between the vapor and liquid at the interface.

Under the above assumptions, the simultaneous heat and mass transfer in the system at steady state is described by the pnergy and diffuston equations. Boundary conditions axe given (1) at the entrance plane, $x=0$, where the temperature and concentration are known; (2) at the wall, $y=0$, where the no-mass-flux condition requires $\partial \mathrm{C} / \partial \mathrm{y}=0$, and where either a temperature is specified (for the constant-temperature wall case) or $\partial \mathrm{T} / \partial \mathrm{y}=0$ (for the adiabatic wall case); and (3) at the vapor-liquid interface, $y=\Delta$, where the concentration and temperature are related to each other through a thermodynamic equilibrium condition, and the heat flux equals the mass flux times the heat of absorption of the vapor in the solution. Thus, the two pquationo can ue solved tor the two unknown variables, temperature and concentratlon, and their distribution in the film can be obtained.

The model developed is quite general and may be solved for a variety of flow regimes (laminar, turbulent, transitinn) and fluid properties. It can be extended to other wall and interface conditions. In our first solution, described in this report, the energy and diffusion equations were solved for laminar flow. A numerical solution based on finite 
differences in a two-dimensional grid and an analytical solution based on a series of eigenfunctions were developed and agreed very well. In addition, an integral method was employed which made it possible to obtain approximate analytical expressions for most parameters of interest. The solution was carried out for a linear absorbent - a mixture with a linear temperature-concentration equilibrium relation and a constant heat of absorption. The techniques of solution are suitable, however, for nonlinear absorbents with given characteristics.

The solution describes the development of the thermal and concentration boundary layers and the variations of the temperatures, concentrations, and heat and mass fluxes. These quantities in their normalized, dimensionless forms depend on two characteristic parameters of the system: the Lewis number Le and the dimensionless heat of absorption $\lambda$. The length in the direction of flow is normalized with respect to the Peclet number and the film thickness.

The model shows the existence of two boundary layers, of temperature and of concentration, which develop as the absorption effects at the interface diffuse toward the wall. The former normally develops considerably faster than the latter since the Lewis number (ratio of mass to thermal diffusivities) is usually small, on the order of $10^{-3}$. The gradients in the temperature and concentration profiles are sharp for small lengths near the entrance plane and flatten out with distance. The general dependence of the temperature and concentration on the normalized length $\zeta=(\mathrm{x} / \Delta \cdot \mathrm{Pe})$ is described in this paper for a typical set of values of the parameters le and $\lambda$. Initial1y, for small $\zeta$, the behavior is the same for both constant-temperature and adiabatic walls. Thermodynamic equilibrium is reached at the interface immediately upon contact with the vapor, but it takes some distance for the effect to diffuse into the fi.lm and be felt at the wall. As $\zeta$ increases, the wall, bulk, and interface temperatures and concentrations vary toward a final. common value. In the constant-temperature wall case, the dimensionless temperature and concentration reach asymptotic values of 0 and 1 , respectively. In the adiabatic wall case, the asymptotic temperature and concentration are $\lambda /(\lambda+$ Le $)$ and $L e /(\lambda+L e)$, respectively. 
Heat and mass transfer coefficients for the system were calculated. The Sherwood number for mass transfer from the vapor-liquid interface to the bulk of the film reaches an asymptotic value of 3.45 , with fully developed boundary layers for the constant-temperature wall. Lower values are obtained for the adiabatic wall. Under the same conditions, the Nusselt number for heat transfer from the interface to the bulk reaches values of 4.23 and 2.65 for the adiabatic and constant-temperature wall, respectively. The Nusselt number for heat transfer from the bulk to the wall reaches 1.60 . 


\section{INTRODUCTION}

Absorption of gases and vapors into liquids is encountered in numerous applications in chemical technology. These processes normally involve simultaneous heat and mass transfer within the gas-liquid system. The heat of absorption gives rise to temperature gradients leading to heat transfer; the temperature influences the vapor pressure and concentration equilibrium between the two phases, which in turn affects the exchange of mass.

The combined heat and mass transfer process does not lend itself easily to mathematical analysis. Many studies of absorption problems have considered the heat and the mass transfer separately, neglecting the coupling between them. Fortunately, in many cases the heat interaction is small, so the process may be considered isothermal. In some processes, however, the effect of heat transfer is important and cannot be neglected. A typical example is when the absorbate is a vapor with high heat of absorption, such as water. Furthermore, there is growing interest in processes in which mass transfer is initiated specifically to produce a temperature change. One such example, from which this study originated, is of absorption heat pumps for heating and cooling; the heat transfer accompanying the mass transfer is of primary importance.

The gas-liquid contactors in which absorption takes place are typically spray, trayed, or packed towers. Of particular interest are systems involving falling liquid films, which have found wide application in modern equipment. Many studies, using different flow regimes, geometries, and boundary conditions, have been performed on gas absorption in liquid films. Chien and Ibele did a comprehensive survey of the hydrodynamics of falling films. ${ }^{1}$ As early as 1940, Vyazovov formulated a simple model for isothermal absorption in a falling film, which was shown by comparison with experimental results to provide rough estimates for the mass transfer coefficients. ${ }^{2}$ Improved and more elaborate models have been since developed. Olbrich and Wild provided a solution to the diffusion equation in laminar flow for several falling film geometries; the solution, in the form of a series of eigenfunctions, includes ten 
eigenvalues and coefficients. ${ }^{3}$ Rotem and Neilson added to the laminar solution the diffusion in the direction of flow, which turns out to be negligible for large enough Peclet numbers. 4 "Tamir and Taitel extended the laminar flow solution to cases involving interfacial resistance. 5 Chavan and Mashelkar et al. considered absorption in non-Newtonian 11quids, and Sandall and his co-workers studied turbulent flows.6-10 All these studies deal with mass transfer only, under conditions where heat transfer has no effect.

Only recently has some work been published on rombined heat aud mass transfer in falling films. Yih and Seagravc analyzesl a laminar fluw problem and studied the effect of a temperature gradient on the absorption process. 11 Neglecting temperature variations in the direction of. flow, they essentially assumed a linear temperature profile across the film thickness. The temperature variation in their model influenced the process through its effect on the physical properties of the liquid. Nakoryakov and Grigor'eva used a similar approximate approach and also assumed a linear temperature profile across the film.12 In their model, however, temperature variations in the direction of flow were not neglected. Two later and improved models by the same authors have calculated, rather than assumed, the actual shape of the temperature profile, which led to more accurate results.13,14 in ref. 13 an eigenfunction geries sulution is given for the coupled diffusion and energy equations for an impermeable, constant-temperature wall and an equilibrium boundary condition at the liquid-vapor interface. In ref. 14 an analytic solution was obtained for the tomperature and concentration variation near the entrance region. The main limitation of these models is their assumption of a uniform velocity profile in the film, whereas the actual velocity profile in laminar flow ic parabolic. This assumption leads to a deviation of about $20 \%$ in the heat and mass transfer coefficients and to underprediction by about $40 \%$ of the distance required for boundary layer development. The models are also restricted to a constant-temperature wall. 13,14

The present study originated from work at Oak Ridge National Laboratory (ORNL) on absorption heat pumps. Although some scattered data are available on the design of absorbers and desorbers for these systems, it was 
recognized that fundamental, quantitative information on the combined heat and mass transfer process is lacking. This report is an attempt to improve on the models described earlier and to remove some of their limitations. The model, for a falling film of absorbent solution in laminar flow, calculates the heat and mass transfer coefficients for typical wall conditions and finds their dependence on the system's parameters. 
THIS PAGE

\section{WAS INTENTIONALLY LEFT BLANK}




\section{MODEL AND EQUATIONS}

The system analyzed is described schematically in Fig. 1. A film of liquid solution, composed of substances I (absorbent) and II (absorbate),

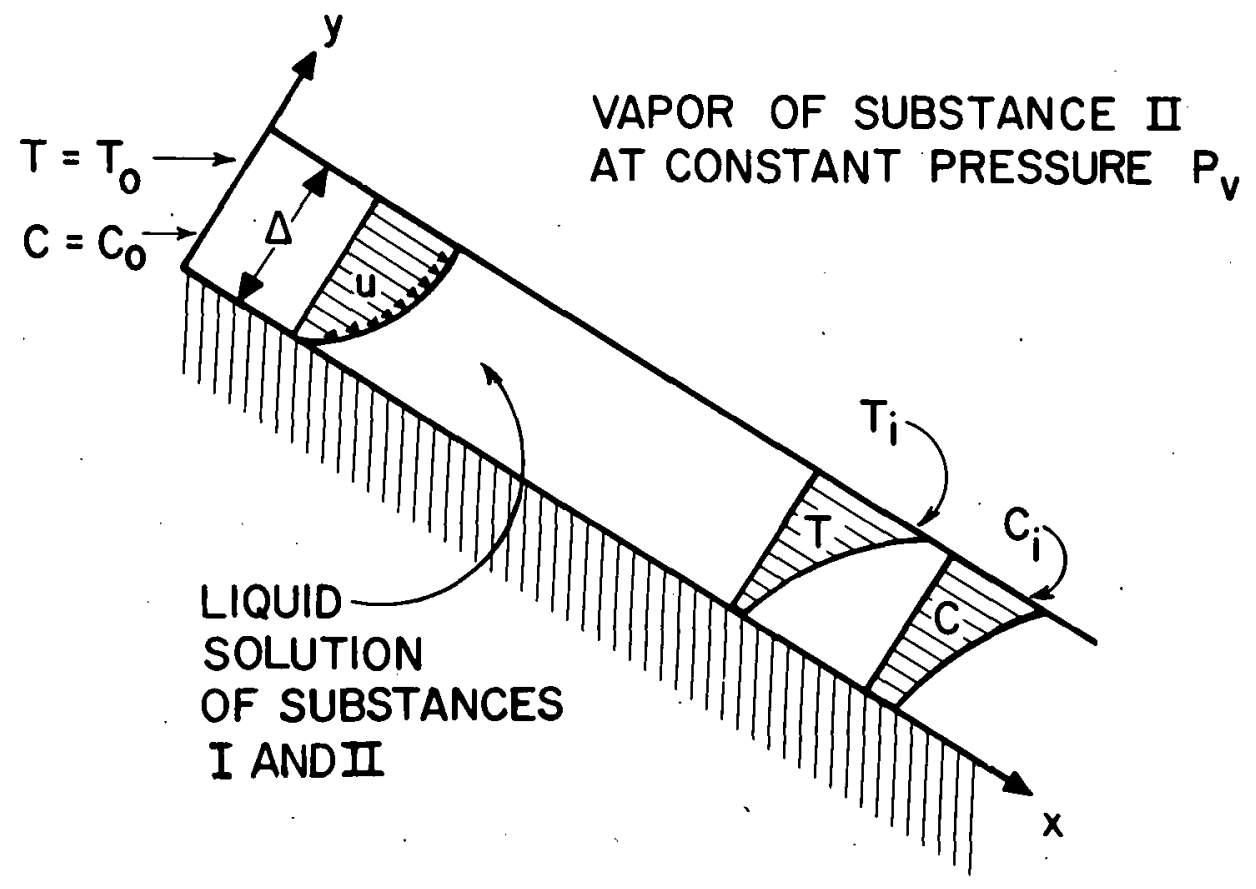

Fig. 1. Description of falling film of absorbent in contact with aboorbatc. Typical proflles of velocity, temperature, and concentration are shown.

flows down over an inclined plane. Substance I remains in the liquid phase; substance II may be absorbed into the solution. The film is in contact with the stagnant vapor of substance II at constant pressure $P_{v}$. At $\mathrm{x}=0$, the liquid solution is at a uniform temperature $\mathrm{T}_{0}$ and composition $C_{o}$ (moles of substance II per unit volume of mixture) corresponding to an equilibrium vapor pressure $P_{\text {vo }}$ different from $P_{v} \cdot$ Because of this difference, a mass transfer process takes place at the liquidvapor interface. The substance absorbed at the interface diffuses into the film; the heat generated in the absorption results in a simultaneous heat transfer process. Two cases of practical interest are considered: in one, the wall 1 s kept at a constant temperature $\mathrm{T}_{0}$; in the other, the wall is adiabatic. 
The flow of the liquid film is assumed to be laminar, one-dimensional, and fully developed throughout. No shear forces are exerted on the liquid by the vapor. The film thickness can be easily determined from the mass flow rate, density, viscosity, and angle of inclination (e.g., ref. 1). The velocity profile, shown in Fig. 1, is parabolic and given by

$$
\mathrm{u}=\frac{3}{2} \overline{\mathrm{u}}\left[2\left(\frac{\mathrm{y}}{\Delta}\right)-\left(\frac{\mathrm{y}}{\Delta}\right)^{2}\right],
$$

where $\vec{u}$ is the average flow velocity, equal to the mass flow rate per unit breadth, divided by the density and film thickness.

In formulating this model, the following assumptions have been made:

1. The liquid solution is Newtonian, and its physical properties are constant and independent of temperature and concentration.

2. The mass of vapor absorbed per unit time is small compared with the mass flow rate of the liquid. Therefore, it is assumed that the latter, the film thickness, and the average flow velocity are cinstant.

3. There is no heat transfer in the vapor phase.

4. There are no natural convection effects in the film due to temperature or concentration differences. (This assumption is in fact. a corollary of the first one.)

5. Diffusion thermal effects are negligible.

6. Vapor pressure equilibrium exists between the vapor and 11quid at the interface.

Under these assumptions, the simultaneous heat and mass transfer in the system at steady state is described by the energy and diffusion equations:

$$
\begin{aligned}
& u \frac{\partial T}{\partial x}=\alpha \frac{\partial^{2} T}{\partial y^{\underline{Z}}}, \\
& u \frac{\partial C}{\partial x}=D \frac{\partial^{2} C}{\partial y^{2}},
\end{aligned}
$$


where diffusion and heat conduction in the $\mathrm{x}$-direction have been neglected with respect to those in the y-direction. The following boundary conditions apply:

$$
\begin{aligned}
& \mathrm{T}=\mathrm{T}_{\mathrm{O}} \text { and } \mathrm{C}=\mathrm{C}_{\mathrm{o}} \text { at } \mathrm{x}=0 \text {; } \\
& \frac{\partial C}{\partial y}=0 \\
& \mathrm{~T}=\mathrm{T}_{\mathrm{o}} \text { for constant temperature wall, }\{\text { at } \mathrm{y}=0 \text {; } \\
& \text { or } \\
& \partial \mathrm{T} / \partial \mathrm{y}=0 \text { for adiabatic wall, } \\
& \mathrm{T}=\mathrm{T}_{i} \text { and } \mathrm{C}=\mathrm{C}_{i} \text { at } \mathrm{y}=\Delta
\end{aligned}
$$

Here $T_{i}$ and $C_{i}$ are the interfacial temperature and concentration, both unknown functions of $\mathrm{x}$. They are related to each other and to the interfacial mass flux $n_{i}$, also unknown, by the following conditions:

$$
\begin{aligned}
& F\left(T_{i}, C_{i}\right)=P_{v}=\text { constant, } \\
& D(\partial C / \partial y)=n_{i} \quad \text { at } y=\Delta, \\
& k(\partial T / \partial y)=n_{i} \bar{H}_{a}\left(T_{i}, C_{i}\right) \quad \text { at } y=\Delta,
\end{aligned}
$$

where $\overline{\mathrm{H}}_{\mathrm{a}}$ is the heat of absorption, per mole of the vapor, in the 1iquid. Equation (5a) represents the condition of vapor pressure equilibrium at the interface; Eqs. ( $5 b$ ) and (5c) describe the mass and heat fluxes, respectively, at the interface. The heat of absorption is defined as

$$
\overline{\mathrm{H}}_{\mathrm{a}}=\overline{\mathrm{h}}_{\mathrm{II}}-\overline{\mathrm{H}}_{\mathrm{II}}\left(\mathrm{C}_{i}, \mathrm{~T}_{i}\right)
$$

where $\bar{h}_{I I}$ is the enthalpy (per mole) of the vapor in contact with the film and $\overline{\mathrm{H}}_{I I}$ is the partial molal enthalpy of substance II at the inter- 
face. The variable $\overline{\mathrm{H}}_{\mathrm{II}}$ is a function of the interfacial temperature and concentration, whereas $\bar{h}_{I I}$ is independent of them. The definition (5d) is more rigorous than the one sometimes found in the literature, in which $\vec{H}_{a}$ is expressed in terms of the latent heat of vaporization and condensation of substance II at temperature $\mathrm{T}_{i}$ minus the differential heat of dilution. This definition would be correct if the vapor were saturated at a temperature equal to that of the liquid interface, but this is generally not the case, nor is it so in the present problem.

The typical shapes of the temperature and concentration profiles in the film are depicted in Fig. 1. Before proceeding with the solution, it would be useful to rewrite the equations in a dimensionless form. The new varlables are defined as

$$
\begin{aligned}
& \zeta=\frac{1}{P_{e}} \frac{x}{\Delta}, \quad \eta=\frac{y}{\Delta} ; \\
& v=u / \bar{u}=\frac{3}{2}\left(2 \eta-\eta^{2}\right) ; \\
& \theta=\frac{T-T_{o}}{T_{e}-T_{o}}, \quad \gamma=\frac{C-C_{o}}{C_{e}-C_{o}} ;
\end{aligned}
$$

where $\mathrm{T}_{e}$ is the equilibrium temperature of the solution at concentration $\mathrm{C}_{\mathrm{o}}$ with the vapor, and $\mathrm{C}_{\mathrm{e}}$ is the concentration of the solution al temperature $T_{0}$ in equillbriuin with elue varr. The varishlos $T_{e}$ and $r_{c}$ have a physical significance: $T_{e}$ is the temperature the film would reach if thermodynamic equilibrium could be achieved without change in concentration. $\mathrm{C}_{\mathrm{H}}$ is the concentration that would be tedulied if thermodynamic equilibrium could be achieved without change in temperature. Both are limiting cases to what actually happens in the simultaneous heat and mass transfer process.

Equations (2) and (3), with the new dimensionless variables, become

$$
\begin{aligned}
& v \frac{\partial \theta}{\partial \zeta}=\frac{\partial^{2} \theta}{\partial \eta^{2}}, \\
& v \frac{\partial \gamma}{\partial \zeta}=\operatorname{Le} \frac{\partial^{2} \gamma}{\partial \eta^{2}},
\end{aligned}
$$


where Le is the Lewis number. The boundary conditions now have the dimensionless form

$$
\begin{aligned}
& \theta=0 \text { and } \gamma=0 \text { at } \zeta=0 ; \\
& \frac{\partial \gamma}{\partial \eta}=0 ; \\
& \theta=0 \quad \text { for constant temperature wa11, } \\
& \partial \theta / \partial \eta=0 \quad \text { for adiabatic wall, } \\
& \theta=\theta_{i} \text { and } \gamma=\gamma_{i} \text { at } \eta=1 ;
\end{aligned}
$$

where $\theta_{i}$ and $\gamma_{i}$ are the dimensionless interfacial temperature and concentration, both unknown functions of $\zeta$, which are related to each other as follows:

$$
\begin{aligned}
& f\left(\theta_{i}, \gamma_{i}\right)=0 \quad \text { (equilibrium condition), } \\
& \partial \gamma / \partial \eta=\mu_{i}=\frac{n_{i} \Delta}{D\left(C_{e}-C_{o}\right)} \text { at } n=1, \\
& \frac{\partial \theta}{\partial \eta}=\mu_{i} \lambda\left(\theta_{i}, \gamma_{i}\right)=\mu_{i} L e \frac{\bar{H}_{a}\left(C_{e}-C_{o}\right)}{\rho c_{p}\left(T_{e}-T_{0}\right)} \text { at } n=1 .
\end{aligned}
$$

Here $\mu_{i}$ is the dimensionless mass flux from the vapor to the film and $\lambda$ is the dimensionless heat of absorption, whirh is a function of $\theta_{i}$ and $\gamma_{i}$

The problem is now well defined mathematically in terms of the two second-order differential Eqs. ( 7$)$ and ( 8 ) and the boundary conditions $(9 a-c)$ for the unknown distributions of $\theta$ and $\gamma$ with $\zeta$ and $n$. The . boundary conditions are given in terms of two additional unknowns, $\theta_{i}$ and $\gamma_{i}$, which are determined along with. $\|_{i}$ from Eqc. (10a-c).

The two cases for which the model was developed (constant-temperature and adiabatic walls) are of practical interest in actual working systems. The former simulates a process in which the liquid is constantly cooled during absorption, such as in absorption chillers and heat pumps. The 
latter represents a case in which the process occurs without cooling, such as in many gas-1iquid contactors. We have assumed that the constanttemperature wall is at temperature $T_{0}$ equal to that of the entering solution. If this is not the case, the results will vary somewhat because of an additional pure heat transfer process between the wall and the film near the entrance region. ${ }^{14}$ Also, the adiabatic wall may be considered as a particular case of the more general constant heat flux condition. 


\section{THE LINEAR ABSORBENT}

To proceed with the solution, it is necessary to know the equilibrium relation between the temperature, composition, and vapor pressure of the specific liquid absorbent being used. This relation, expressed in a dimensionless form for the parameters at the interface, yields Eq. (10a). In addition, it is necessary to express the dimensionless heat and absorption $\lambda$ in terms of $\theta_{i}$ and $\gamma_{i}$ for the given materials. Data on equilibrium properties have been compiled from experimental and theoretical studies and are available in the literature for many liquidvapor combinations.

A universal relation between the temperature, concentration, and vapor pressure in equilibrium can be formulated which would fit a large number of absorbents within a limited range of the preceding parameters. This relation indicates a linear dependence between the temperature, the concentration, and the logarithm of the vapor pressure. A thermodynamic justification for this relation, limited to electrolytic solutions, is given below, based on the definition of the osmotic coefficient and the Clapeyron equation. Similar behavior is exhibited by some other, nonelectrolytic absorbents.

The osmotic coefficient $\phi$ of a solution composed of a solvent (substance II) and a single electrolyte (substance I) which dissociates into $\nu$ ions is defined by ref. 15:

$$
-\phi \cup \mathrm{m}=\frac{1.000}{M_{I I}} \ln \left(\mathrm{a}_{I I}\right)
$$

where $\mathrm{m}$ is the molality of the solution, related to the solvent concentration $\mathrm{C}$ by .

$$
\mathrm{m}=\frac{1}{M_{I}}\left(1000-\frac{\mathrm{M}_{I I} \mathrm{C}}{\rho}\right) \text {. }
$$

The activity of the solvent $a_{\text {II }}$ may be expressed in terms of the vapor pressure as

$$
\mathrm{a}_{\mathrm{II}}=\mathrm{P}_{\mathrm{v}} / \mathrm{P}_{\mathrm{v}}^{\mathrm{O}}
$$


where $\mathrm{P}_{\mathrm{v}}{ }^{\mathrm{O}}$ is the vapor pressure of substance II in its pure state, at the given temperature. Substituting Eqs. (12) and (13) into Eq. (11) yields

$$
\ln \frac{\mathrm{P}_{\mathrm{v}}}{\mathrm{P}_{\mathrm{v}}^{\mathrm{o}}}=-\phi \nu \frac{\mathrm{M}_{\mathrm{II}}}{\mathrm{M}_{\mathrm{I}}}\left(1-\frac{\mathrm{CM}_{\mathrm{II}}}{1000 \rho}\right)
$$

The vapor pressure of the pure substance II may be expressed in terms of temperature by means of the Clapeyron equation:

$$
\ln \frac{\mathrm{P}_{\mathrm{V}}^{\circ}}{\mathrm{r}_{\mathrm{O}}}=\frac{\mathrm{h}_{\mathrm{fgo}}}{\mathrm{RT}_{0}^{2}}\left(T-\mathrm{T}_{0}\right)
$$

where $\mathrm{P}_{\circ}$ is the vapor pressure at the temperalure of origin $\mathrm{T}_{0}$, and $\mathrm{h}_{\mathrm{fgo}_{\mathrm{o}}}$ is the latent heat of vaporization at this temperature, assumed to remain constant over a limited temperature range. The same assumption can be applied to the osmotic coefficient. Thus, by adding Eqs. (14) and (15), we obtain the following linear relation between the temperature, concentration, and logarithm of vapor pressure:

$$
\ln \frac{\mathrm{P}_{y}}{\mathrm{P}_{\mathrm{o}}}=-\phi \nu \frac{\mathrm{M}_{\mathrm{TT}}}{\mathrm{M}_{I}}\left(1-\frac{\mathrm{CM}_{\mathrm{II}}}{1000 \rho}\right)+\frac{\mathrm{h}_{\mathrm{fgo}}}{\mathrm{RT}_{\mathrm{o}}{ }^{2}}\left(\mathrm{~T}-\mathrm{T}_{\mathrm{o}}\right) .
$$

The validity of Eq. (16) was checked for a number of common absorbents, including $\mathrm{LiBr}-\mathrm{H}_{2} \mathrm{U}$, $\mathrm{LICl}-\mathrm{II}_{2} \mathrm{O}$, and $\mathrm{CuCl}_{2}-\mathrm{H}_{2} \mathrm{O}$, and was found to be very good under the above limitations for a wide range of temperatures and concentrations. It should be noted that for ideal solutions or very dilute solutions, Raoult's Law or Henry's Law may be applicable instead of Eq. (16).

The heat of absorption has been defined as the difference between the enthalpy of the vapor $\bar{h}_{I I}$ and the partial molal enthalpy of sulstance II in the liquid $H_{I I}\left[\mathrm{Eq}\right.$. (5d)]. The value $\overline{\mathrm{h}}_{I I}$, which is independent of the interfacial temperature and concentration, is often considerably larger than $\overline{\mathrm{H}}_{\mathrm{II}}$. This is particularly so for vapors of low molecular weight such as $\mathrm{H}_{2} \mathrm{O}$. In those cases, the dependence of $\lambda$ on $\theta_{i}$ and $\gamma_{i}$ is very weak.

We will define a linear absorbent as a material having the followirg properties: 
1. The relation between the temperature and concentration in equilibrium with vapor at constant pressure is linear, of the form

$$
\mathrm{C}=\mathrm{C}_{1} \mathrm{~T}+\mathrm{C}_{2}
$$

2. The heat of absorption is constant and independent of the temperature and concentration.

Then, for a linear absorbent, the dimensionless relation (10a) becomes

$$
\gamma_{i}=1-\theta_{i},
$$

and

$$
\lambda=\text { constant } .
$$


THIS PAGE

\section{WAS INTENTIONALLY LEFT BLANK}




\section{EXACT SOLUTION}

Two different methods of reaching a solution were used to obtain the temperature and concentration distributions in the film: analytical and numerical. A linear absorbent was assumed in both cases, and the results of the two methods were in excellent agreement. The equations in effect are (7) and (8) with the boundary conditions (9a) and (9b) at the entrance plane and the wall, respectively. The condition (9c) at the interface for the case of a linear absorbent becomes

$$
\theta+\gamma=1 \text { and } \frac{\partial \theta}{\partial \eta}=\lambda \frac{\partial \gamma}{\partial \eta} \text { at } \eta=1 .
$$

\subsection{Analytical Solution}

The approach to the solution is similar to the one employed in ref. 13 for the case with the uniform velocity profile. Using the Fourier method, we write a separation-of-variables solution for Eqs. (7) and (8), in the form of two infinite series of eigenfunctions, as follows:

$$
\begin{aligned}
& \theta=\sum_{n=1}^{\infty} A_{n} F_{n}(n) e^{-\alpha_{n}{ }^{2} \zeta}, \\
& \gamma=1-\sum_{n=1}^{\infty} R_{n} f_{n}(n) e^{-\beta_{n}{ }^{2} \zeta},
\end{aligned}
$$

where $\alpha_{n}$ and $\beta_{n}$ are the eigenvalues corresponding to the eigenfunctions $F_{n}$ and $G_{n}$, respectively. The boundary conditions (18), which must be satisfied at any $\tau$, indicate that for every $n, \alpha_{n}=\beta_{n}$. Substituting Eqs. (19a) and (19b) into (7) and (8), we obtain the following equations for the eigenfunctions:

$$
\begin{aligned}
& \frac{\mathrm{d}^{2} \mathrm{~F}}{\mathrm{~d} n^{2}}+\frac{3}{2}\left(2 n \cdot n^{2}\right) \alpha_{n}{ }^{2} \mathrm{~F}_{\mathrm{n}}=0, \\
& \frac{d^{2} G}{d n^{2}}+\frac{3}{2}\left(2 n-n^{2}\right) \frac{\alpha_{n}^{2}}{L e} G_{n}=0,
\end{aligned}
$$


with the boundary conditions at the wall resulting from Eq. (9b)

$$
\begin{aligned}
& G_{n}^{\prime}(0)=0 \text {; } \\
& F_{n}^{\prime}(0)=0 \text { for adiabatic wall, or } F(0)=0 \text { for constant } \\
& \text { temperature wall. }
\end{aligned}
$$

Another boundary condition to be satisfied by Eqs. (20) and (21) is condition (18) at the interface, which yields

$$
\begin{aligned}
& A_{n} F_{n}(1)=B_{n} G_{n}(1), \\
& A_{n} F_{n}^{\prime}(1)=-\lambda B_{n} G_{n}^{\prime}(1) .
\end{aligned}
$$

Nute that equations (23a) and (23b) for $A_{n}$ and $B_{n}$ are homogeneous and have a solution only if the determinant equals zero, namely

$$
\frac{F_{n}^{\prime}(1)}{F_{n}(1)}=-\lambda \frac{G_{n}^{\prime}(1)}{G_{n}(1)}
$$

which is the condition for determining the eigenvalues $\alpha_{n}$ once a solution is obtained for $F_{n}$ and $G_{11}$. The coeffirients $A_{n}$ and $B_{n}$ can then be. determiued frum the boundary condition (9a) hy means of a Sturm Liouville orthogonality condition at $\zeta=0$.

A power series solution to Eq. (20) may be written in the form

$$
F_{n}(n)=\sum_{i=0}^{w} A_{n, i} n^{i},
$$

where, using the boundary condition (22b), we find

$$
\begin{aligned}
& a_{n, 0}=1, \quad a_{n, 1}=0, \quad a_{n, 2}=0, a_{n, 3}=-a_{n}{ }^{2 / 2} \quad \text { for adiabatic wall; } \\
& a_{n, 0}=0, \quad a_{n, 1}=1, \quad a_{n, 2}=0, \quad a_{n, 3}=0 \\
& \text { for constant-temperature wall; } \\
& a_{n, i}=\frac{3}{2} \alpha_{n}{ }^{2} \frac{\left(a_{n, i-4}-2 a_{n, i-3}\right)}{i(i-1)} \text { for } i \geqslant 4, \text { both types of wall. (25b) }
\end{aligned}
$$


Similarly, the solution to Eq. (21) may be written as

$$
G_{n}(n)=\sum_{i=0}^{\infty} b_{n, i} n^{i}
$$

where we find, with the aid of boundary condition (22a) ,

$$
\begin{aligned}
& b_{n, 0}=1, \quad b_{n, 1}=0, \quad b_{n, 2}=0, \quad b_{n, 3}=-\alpha_{n}{ }^{2} / 2 L e ; \\
& b_{n, i}=\frac{3}{2} \frac{\alpha_{n}^{2}}{L e} \frac{\left(b_{n, i-4}-2 b_{n, i-3}\right)}{i(i-1)} \text { for } i \geqslant 4 .
\end{aligned}
$$

The eigenvalues are the roots of Eq. (24). An algorithm may therefore be employed where a guessed value of $\alpha_{n}$ is used in Eqs. (25b) and (26b) to calculate the terms of the series $a_{n, i}$ and $b_{n, i}$, and, hence, the eigenfunctions $F_{n}(1)$ and $G_{n}(1)$. The results are then substituted in Eq. (24). If the latter is not satisfied, a different guess is taken until convergence is obtained.

Table 1 lists the first nine eigenvalues for a set of typical values of the parameters, $\lambda=0.01$ and $L e=0.001$. The table also shows the corresponding coefficients $A_{n}$ and $B_{n}$, which must be calculated to complete the solution. To do so, we must formulate an orthogonality condition at $\zeta=0$, which is of the Sturm-Liouville type yet somewhat different from its standard form because of the coupled boundary condition in Eq. (18).

Consider Eq. (20) for the cigenfunction $F_{n}$; multiplying it by another eigenfunction $F_{m}$ and integrating over the range of $n$ yields

$$
\begin{aligned}
& \frac{3}{2} \alpha_{n}^{2} \int_{0}^{1}\left(2 \eta-\eta^{2}\right) F_{m} F_{n} \cdot d \eta=-\int_{0}^{1} F_{m} F_{n}^{\prime} d \eta \\
& =F_{m}(0) F_{n}^{\prime}(0)-F_{m}(1) F_{n}^{\prime}(1)+\int_{0}^{1} F_{m}^{\prime} F_{n}^{\prime} d \eta
\end{aligned}
$$


Tatle 1. Eigenvalues and coefficients for typical values of the parameters:

$$
\lambda:=0.01 \text {, Le }=0.001
$$

\begin{tabular}{lcccccc}
\hline & \multicolumn{3}{c}{ Adiabatic wal1 } & & \multicolumn{2}{c}{ Constant temperature wa11 } \\
\hline $\mathrm{n}$ & $\alpha_{\mathrm{n}}$ & $\mathrm{A}_{\mathrm{n}}$ & $\mathrm{B}_{\mathrm{r}}$ & $\alpha_{\mathrm{n}}$ & $\mathrm{A}_{\mathrm{n}}$ & $\mathrm{B}_{\mathrm{n}}$ \\
\hline 1 & 0 & 0.90909 & $0.969 C 9$ & 0.05765 & 0.026696 & 1.3373 \\
2 & 0.10225 & -0.14691 & 0.18984 & 0.16052 & 0.025599 & -0.54334 \\
3 & 0.19871 & -0.12853 & -0.19710 & 0.26269 & 0.026061 & 0.35597 \\
4 & 0.29605 & -0.10555 & 0.19098 & 0.36464 & 0.026789 & -0.26809 \\
5 & 0.39449 & -0.08459 & -0.17902 & 0.46640 & 0.027817 & 0.21567 \\
6 & 0.49385 & -0.06756 & 0.16553 & 0.56793 & 0.029115 & -0.17983 \\
7 & 0.59395 & -0.5439 & -0.15237 & 0.66916 & 0.030765 & 0.15338 \\
8 & 0.69463 & -0.04435 & 0.14006 & 0.76997 & 0.032680 & -0.13206 \\
9 & 0.79574 & -0.03667 & -0.12886 & 0.87079 & 0.035654 & 0.12027 \\
\hline
\end{tabular}


Similarly,

$$
\begin{aligned}
& \frac{3}{2} \alpha_{m}^{2} \int_{0}^{1}\left(2 \eta-\eta^{2}\right) F_{n m} F_{m} d \eta=F_{n}(0) F_{m}^{\prime}(0)-F_{n}(1) F_{m}^{\prime}(1) \\
& +\int_{0}^{1} F_{n}^{\prime} F_{m}^{\prime} d \eta .
\end{aligned}
$$

Subtracting Eq. (27b) from (27a) and using the boundary condition (22b), we obtain

$$
\frac{3}{2}\left(\alpha_{n}{ }^{2}-\alpha_{m}{ }^{2}\right) \int_{0}^{1}\left(2 \eta-\eta^{2}\right) F_{n} F_{m} d \eta=F_{n}(1) F_{m}^{\prime}(1)-F_{m}(1) F_{n}^{\prime}(1) .
$$

Repeating the same with Eq. (21) for the eigenfunction $G_{n}$, we find that

$$
\frac{3}{2 L e}\left(\alpha_{n}{ }^{2}-\alpha_{m}{ }^{2}\right) \int_{0}^{1}\left(2 n-\eta^{2}\right) G_{n} G_{m} d \eta=G_{n}(1) G_{m}^{\prime}(1)-G_{m}(1) G_{n}^{\prime}(1) \text {. }
$$

At this point we introduce the coupling between the equations, which is where this orthogonality condition differs from the conventional one. From Eqs. (23a) and (23b),

$$
F_{n}(1) F_{m}^{\prime}(1)-F_{m}(1) F_{n}^{\prime}(1)=-\lambda \frac{B_{n} B}{A_{n} A_{m}}\left[G_{n}(1) G_{m}^{\prime}(1)-G_{m}(1) G_{n}^{\prime}(1)\right] ;
$$

using this condition to combine Eqs. (28a) and (28b) finally yields

$$
\left(\alpha_{n}{ }^{2}-\alpha_{m}{ }^{2}\right) \int_{0}^{1}\left(2 n-n^{2}\right)\left(L e A_{n} A_{m} F_{n} F_{m}+\lambda_{n} B_{n} B_{n} G_{m}\right) d n=0,
$$

which may be written as

$$
\int_{0}^{1}\left(2 n-n^{2}\right)\left(L e A_{n} A_{m} F_{n} F_{m}+\lambda B_{n} B_{m} G_{n} G_{m}\right) d n \mid \begin{aligned}
& =0 \text { for } n \neq m \\
& \neq 0 \text { for } n=m
\end{aligned} .
$$

It should be noted that this type of "coupled" orthogonality condition was developed and used earlier by sparrow and spalding in a problem involving sublimation in a duct. ${ }^{16}$ 
We now return to boundary condition (9a); using Eq. (19), we find

$$
\sum_{n=1}^{\infty} A_{n} F_{n}(n)=0 \text { and } \sum_{n=1}^{\infty} B_{n} G_{n}(n)=1
$$

therefore,

$$
\begin{aligned}
& \sum_{n=1}^{\infty} \int_{0}^{1}\left(2 n-\eta^{2}\right)\left(\operatorname{LeA}_{n} A_{m} F_{n m} F_{m}+\lambda B_{n} B_{m} G_{n} G_{m}\right) d \eta \\
= & \int_{0}^{1}\left(2 n-\eta^{2}\right) \lambda B_{L I} G_{m} d n .
\end{aligned}
$$

Using the orthogonality condition (29b),

$$
\int_{0}^{1}\left(2 n-\eta^{2}\right)\left(\operatorname{LeA}_{n}{ }^{2} F_{n}{ }^{2}+\lambda B_{n}{ }^{2} G_{n}{ }^{2}\right) d n=\int_{0}^{1}\left(2 n-n^{2}\right) \lambda B_{n} G_{n} d \eta \text {, }
$$

which provides one relation between $A_{n}$ and $B_{n}$; a second relation is available in either (23a) or (23b). Solving (31b) and (23a) for $A_{n}$ and $B_{n}$ yields

$$
\begin{aligned}
& B_{11}=\frac{\lambda \int_{0}^{1}\left(2 n-n^{2}\right) G_{n}(n) d n}{\int_{0}^{1}\left(2 n-n^{2}\right)\left[L e \frac{G_{n}^{2}(1)}{F_{n}^{2}(1)} F_{n}^{2}(n)+\lambda G_{n}^{2}(n)\right] d n}, \\
& A_{n}=B_{n} \frac{G_{n}(1)}{F_{n}(1)} .
\end{aligned}
$$

The andyrical solution is now complete. The algorithm mentioned earlier makes it possible to obtain the first few eigenvalues* from Eq. (24) without difficulty for most values of interest of the parameters. This is sufficient for an accurate calculation of $\theta$ and $\gamma$ for moderate and large values of $\zeta$ due to the exponential terms in Eqs. (19a-b). For

*The sequence of the eigenvalues is such that a higher $\mathrm{n}$ corresponds to a larger value of $\alpha_{n}$. 
small values of $\zeta$, however, a large number of eigenvalues is required. The recursive formulas (25b) and (26b) turn out to be unstable for large values of $\alpha_{n}$, and it is increasingly difficult to obtain convergence of the series $(25 a-b)$ and $(26 a-b)$ for the eigenfunctions. An alternative method for obtaining the eigenvalues is through a numerical integration of Eqs. (20) and (21). Rather than doing this, it was found to be more efficient to use a numerical method for solving the original Eqs. (7) and (8) in their partial differential forms, which will be described next. Yet, the analytical eigenvalue solution is very useful for a wide range of the parameters Le and $\lambda$, where enough eigenvalues can be calculated to cover a considerable range of $\zeta$. For the small $\zeta^{\prime} s$, a similarity solution has been obtained similar to the one in ref. 14, which will also be described below.

\subsection{Numerical Solution}

The numerical technique used to solve the partial differential Eqs. (7) and (8) was based on the so-called "miethod of lines" or "semidiscretization."l7 The $\zeta-n$ plane of the $\mathrm{film}$ was divided into thin strips by means of lines parallel to the $\zeta$ axis. This discretization of the $n$-coordinate made it possible to express the second-order derivative with respect to $n$ in each of the equations in a finite-difference form. Thus, a first-order ordinary differential equation, in $\zeta$ alone, was obtained along each line. Such an equation could be readily solved by means of an available ordinary differential equation integrator using the boundary condition (9a). The integrator selects automatically the required step in $\zeta$ and varies it as necessary as the integration proceeds.

Some difficulty in applying this numerical method to the entire domain resulted from a singularity at the point $\zeta=0, n=1$. This is a singularity of the type of ten encountered in boundary layer problems and is due to a discontinuity in the temperature and concentration between the interface and the entrance plane at this point. To overcome this problem, an analytical solution applicable close to the singular point was developed, which made it possible to calculate the values of the variables at some finite dictance away from the point and begin the 
numerical solution from there. The analytical solution is similar to the one used in ref. 13 and will be described briefly here.

By defining a new variable

$$
n_{1}=1-n \text {, }
$$

and recognizing that the term $\left(2 n-n^{2}\right)$ is very close to unity near the singular point, we can rewrite Eqs. (7) and (8) as

$$
\begin{aligned}
& \frac{3}{2} \frac{\partial \theta}{\partial T}=\frac{\partial^{2} \theta}{\frac{\partial{ }_{11}{ }^{2}}{1}}, \\
& \frac{3}{2} \frac{\partial \gamma}{\partial \zeta}=\operatorname{Le} \frac{\partial^{2} \gamma_{r}}{\partial \eta_{1}^{2}},
\end{aligned}
$$

where the boundary conditions (9b) and (18) now apply at $\eta_{1} \rightarrow \infty$ and $\eta_{1}=0$, respectively. It is then possible to find a similarity variable, combining both $\zeta$ and $\eta_{1}$, for each of the equations and to convert them from partial to ordinary ones. Using the common similarity technique, Eq. (34) becomes

$$
\frac{d^{2} \theta}{d z^{2}}=-2 z \frac{d \theta}{d z}
$$

where $z=n_{1} / \sqrt{8 \zeta / 3}$. Eq. (34a) may be integrated twice to give

$$
\theta=k_{1} \operatorname{erf}(z)+k_{2}=k_{1} \text { erf }\left(n_{1} / \sqrt{8 \zeta / 3}\right)+k_{2} \text {. }
$$

In a similar manner we find from Eq. (35) that

$$
r=k_{3} \text { erf }\left(n_{1} / \sqrt{8 \mathrm{Le} \zeta / 3)}+k_{4}\right.
$$

where $k_{1}, k_{2}, k_{3}$, and $k_{4}$ are constants of integration. Applying the boundary condition ( $9 a$ ) yields $k_{1}=-k_{2}$ and $k_{3}=-k_{4}$ since erf $(\infty)=1$. The boundary condition ( $9 b)$ is satisfied automatically for both the adiabatic and constant-temperature walls. Then, applying the boundary condition (18) yields $k_{1}+k_{3}=-1$ and $k_{1}=\lambda k_{3} / \sqrt{\text { Le }}$ from which all the constants of integration can finally be determined. Thus, we obtain the 
following expressions for the dimensionless temperature and concentrations, in terms of the original variables:

$$
\begin{aligned}
& \theta=\frac{\lambda}{\lambda+\sqrt{L e}}\left[1-\operatorname{erf} \sqrt{\frac{3(1-\eta)^{2}}{8 \zeta}}\right], \\
& \gamma=\frac{\sqrt{L e}}{\lambda+\sqrt{L e}}\left[1-\operatorname{erf} \sqrt{\frac{3(1-n)^{2}}{8 L e \zeta}}\right],
\end{aligned}
$$

which are valid for small $\zeta$, for both the adiabatic and constant-temperature wall cases. This is to be expected, since the effect of the wall cannot be felt until the boundary layer developing from the interface has had enough distance to fill the entire film thickness.

The similarity solution for a small value of $\zeta$ has made it possible to use the numerical technique described earlier and to overcome the problem associated with the discontinuity at the point $\zeta=0, n=1$. In addition, this solution is used to complement the eigenvalue solution whose usefulness at small $\zeta$ was limited by the number of obtainable. eigenvalues. 
THIS PAGE

\section{WAS INTENTIONALLY LEFT BLANK}




\section{RESULTS AND DISCUSSION}

Figures 2 and 3 describe the general behavior of the temperature and concentration in the system as they vary with the normalized length

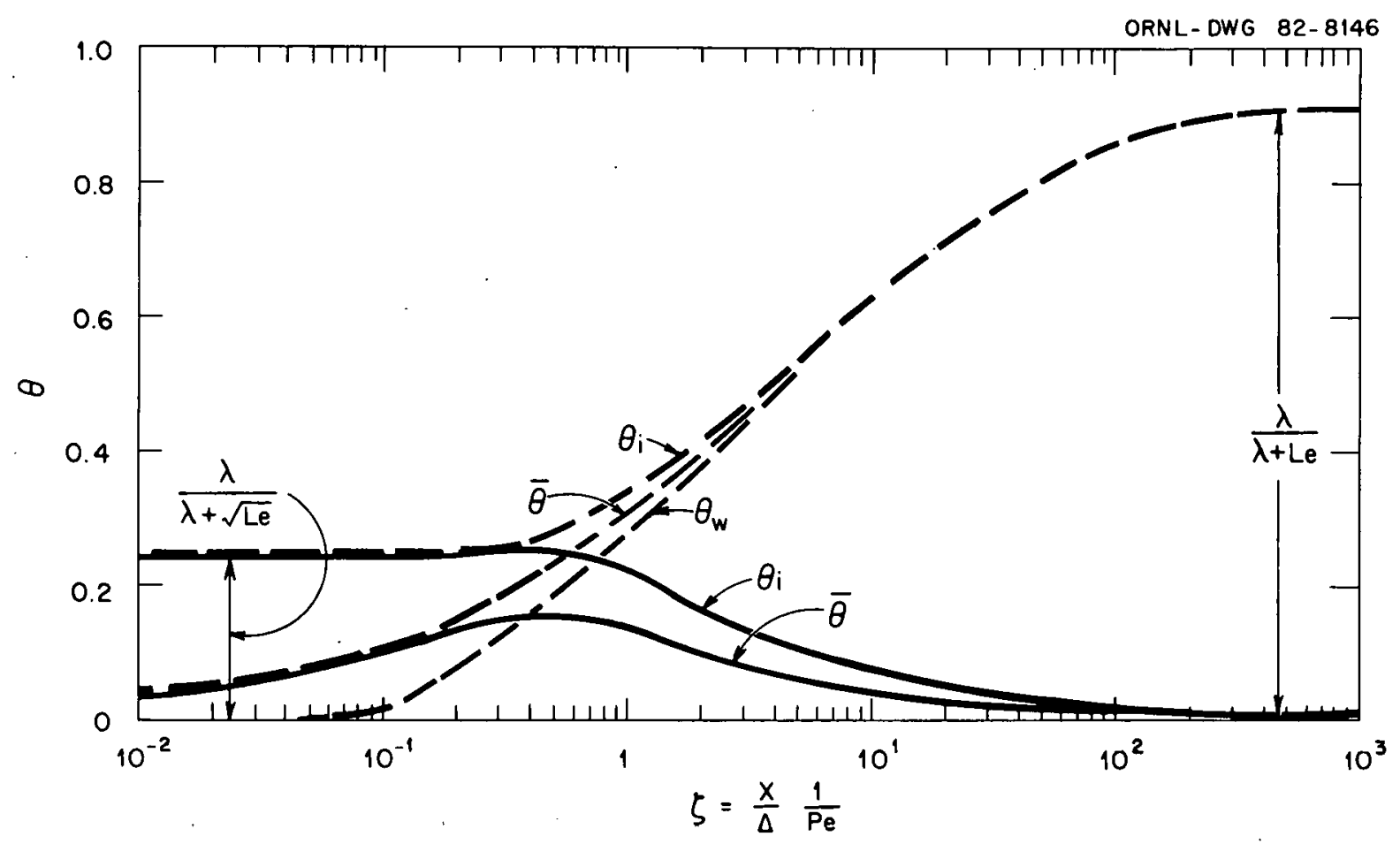

Fig. 2. Dimensionless wa11, liquid bulk, and interface temperatures as functions of the normalized length $\zeta$ for $L e=0.001$ and $\lambda=0.01$. Broken lines describe adiabatic wall; solid lines describe constanttemperature wall.

$\zeta$, for a typical set of values of the parameters Le and $\lambda$. Curves are given for $\theta$ and $\gamma$ at the wall $\left(\theta_{w}, \gamma_{w}\right)$, the liquid bulk $(\bar{\theta}, \bar{\gamma})$, and the liquid-vapor interface $\left(\theta_{i}, \gamma_{i}\right)$. The solid lines describe the results for the constant-temperature wall and the broken lines for the adiabatic wall. This notation will be maintained for the rest of the curves in this section.

Initially, for very small $\zeta$, the behavior is the same for the adiabatic and constant-temperature wall cases. The liquid at the interface reaches thermodynamic equilibrium with the vapor immediately upon contact at $\zeta=0$, but it takes some distance for the effect to diffuse 


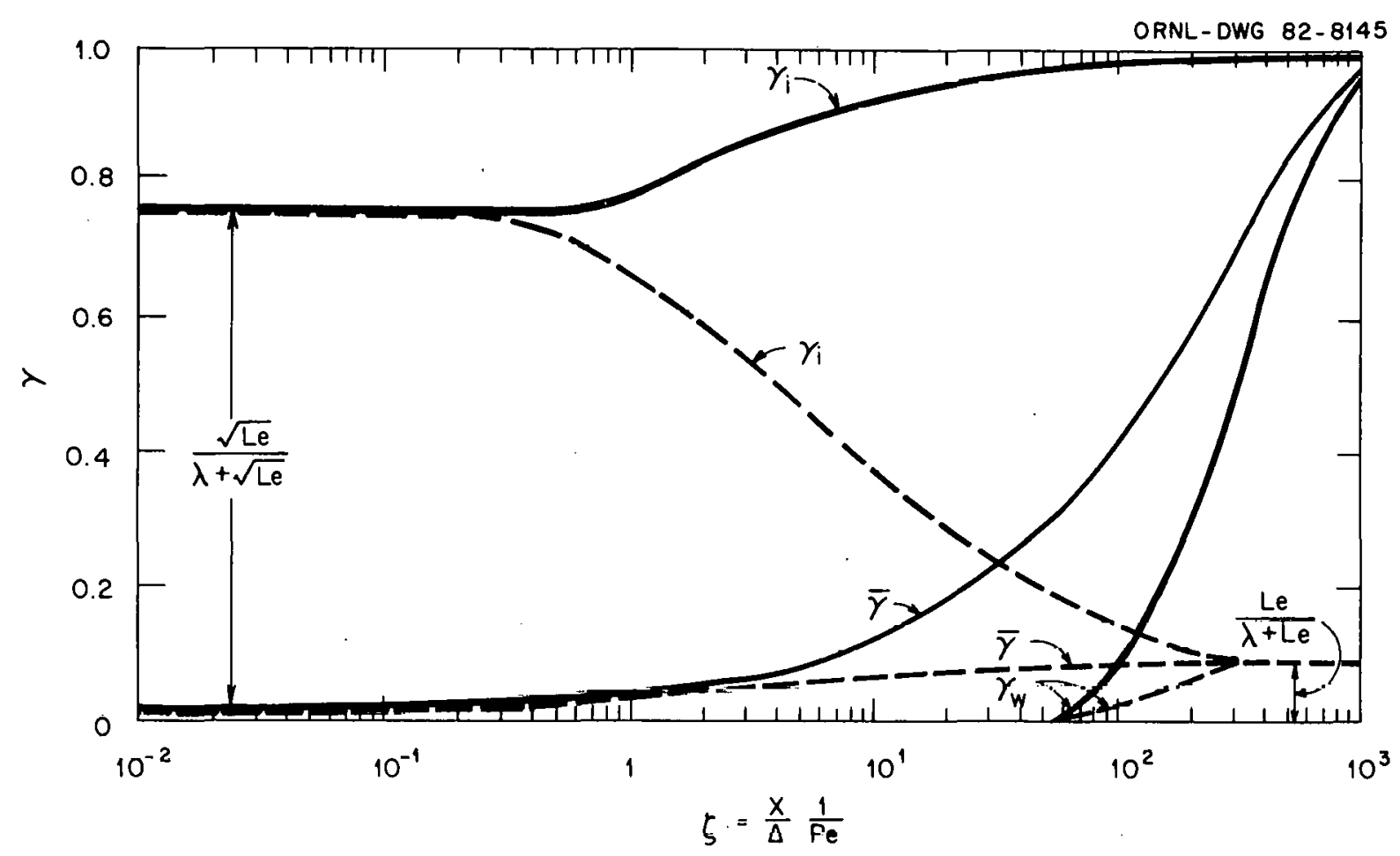

Fig. 3. Dimensionless wall, liquid bulk, and interface concentrations as functions of the normalized length $\zeta$ for Le $=0.001$ and $\lambda=0.01$. Broken lines describe adiabatic wall; solid lines describe constant-temperature wall.

into the film and be felt at the wall. Consequently, $\theta_{w}$ and $\gamma_{w}$ remain essentially zero for small $\zeta$ while $\theta_{i}$ and $\gamma_{i}$ remain almost constant at their initial values reached at $\zeta=0$. These values are $\lambda /(\lambda+\sqrt{\mathrm{Le}})$ and $\sqrt{\mathrm{Le}} /(\lambda+\sqrt{\mathrm{Le}})$, respectively, as we find from the similarity solution for small $\xi$, Eqs. (36) and (37).

As $\zeta$ increases for the adiabatic wall case, the wall, bulk, and interface temperatures increase monotonically toward a final common value and become closer and closer to each other. This steady increase occurs because the heat of absorption is not being removed from the system. For the constant-temperature wall, the interface temperature increases slightly, following the trend of small $\zeta$, and the bulk temperature attempts to approach it as heat is conducted from the interface into the $\mathrm{f} 1 \mathrm{~m}$. Then, both temperatures decrease toward zero as heat flows out of the system through the wall. The interfacial concentration in both cases follows a trend opposite to that of the interfacial tem- 
perature, since $\gamma_{i}=1-\theta_{i}[\mathrm{Eq} .(18)]$. The bulk concentration increases in both cases toward a final value equal to that of $\gamma_{i}$. Note that in the adiabatic wall case $\bar{\gamma}$ increases with $\zeta$, while $\gamma_{i}$ decreases.

The asymptotic values of the dimensionless temperature and concentration may be found from the eigenvalue solution by substituting $\zeta \rightarrow \infty$ in Eqs. $(19 a-b)^{-}$. In the constant-temperature wall case, the dimensionless temperature becomes equal to that of the wall $(\theta=0)$, and the concentration reaches the corresponding equilibrium value $(\gamma=1)$. In the adiabatic wall case, the asymptotic temperature reflects some increase from the initial value $[\theta=\lambda /($ Le $+\lambda)]$, and the corresponding equilibrium concentration $[\gamma=\operatorname{Le} /(\lambda+\mathrm{Le})]$ is lower than the thermodynamically possible value of 1 .

Figures 4 and 5 describe typical temperature and concentration profiles across the film for typical values of $\zeta$. At small $\zeta$ the gradients of both quantities are very sharp and their variations are


Fig. 4. Typical profiles of dimensionless temperature and concentration across the film at different values of $\zeta$ for adiabatic wall where Le $=0.001$ and $\lambda=0.01$. 



Fig. 5. Typical profiles of dimensionless temperature and concentration across the film at different values of $\zeta$ for constant-temperature wall where Le $=0.001$ and $\lambda=0.01$.

limited to a thin layer near the interface. As $\zeta$ increases, the effects at the interface diffuse toward the wall and the gradients become more moderate. There are, in fact, two boundary layers, one of temperature and one of concentration, which develop starting from the point of discontinuity $(\zeta=0, \eta=1)$. The former develops considerably faster than the latter, as the thermal diffusivity $\alpha$ is larger than the mass diffusion inefriblunt D.

The effect of the heat of absorption $\lambda$ is illustrated in Figs. 6 and 7 , describing the temperature and concentration at the interfacc and at the wa11, respertively. In the former, eacli curve rcpresents eillier $\theta_{i}$ or $\gamma_{i}$ when read on the corresponding scale, since $\theta_{i}+\gamma_{i}=1$. The initlal value $(\zeta=0)$ of the interface temperature increases with $\lambda$, and that of the interface concentration decreases, acrording to the formulas shown in Figs. 2 and 3. The same is true for the asymptotic values of temperature and concentration, respectively, both at the interface and at the wall. The heat of absorption $\lambda$ does not seem to 


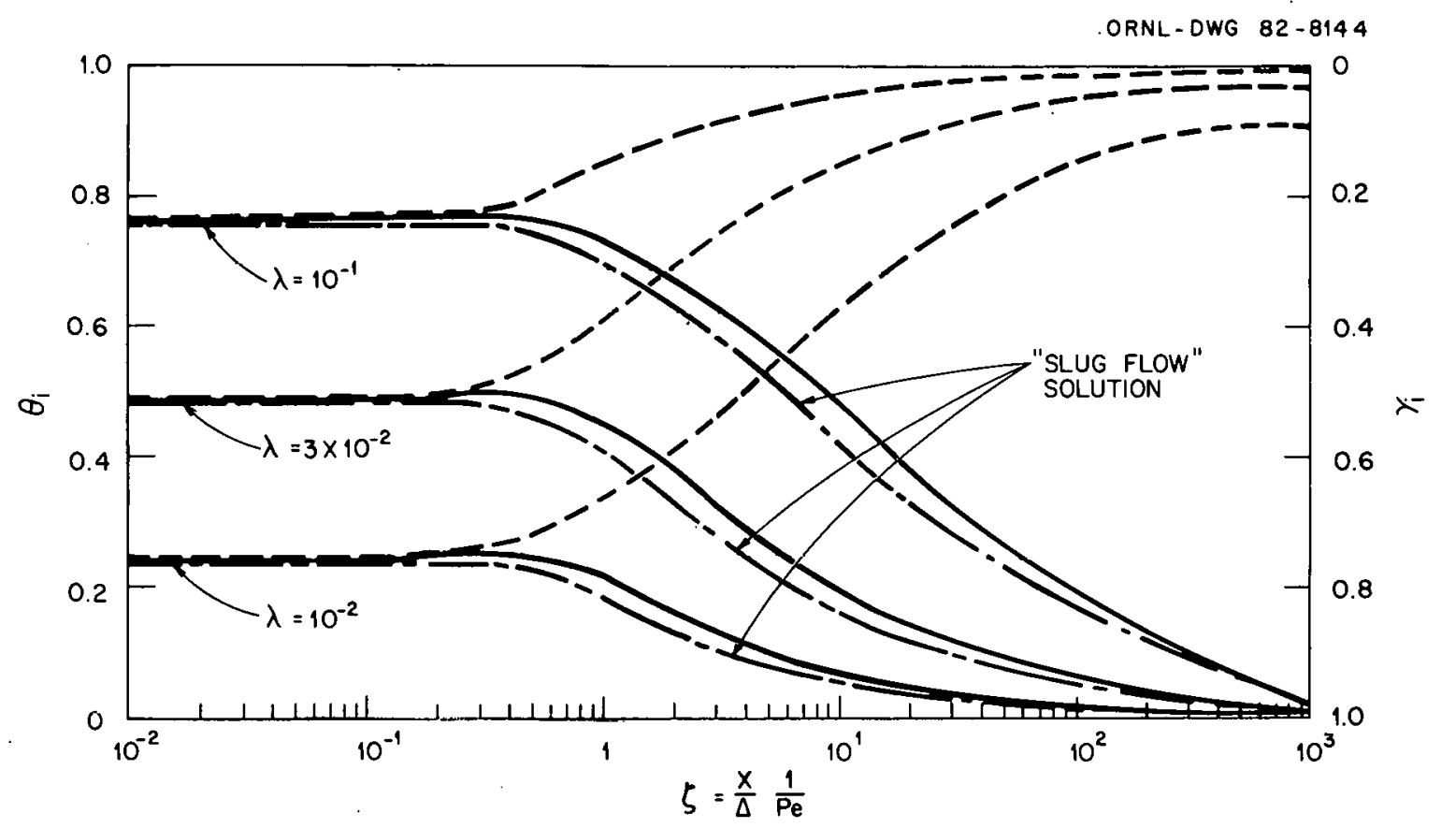

Fig. 6. Dimensionless interface temperature and concentration as functions of the normalized length $\zeta$ for Le $=0.001$ and different values of $\lambda$. Broken lines describe adiabatic wall; solid lines describe constant-temperature wall. The "slug flow" solution by Grigor'eva and Nakoryakov for the constant-temperature wall is plotted for comparison. 13

have an effect on the distance required for the boundary layers to develop. Figure 7 indicates variations in wall temperature and concentration beginning approximately at the same value of $\zeta$ for all values of $\lambda$. At the limit of $\lambda=0$ (negligible heat of absorption), $\theta$ is zero throughout the film, $\gamma_{i}=1$. for all $\zeta$, and $\gamma_{w}$ varies as illustrated in Fig. 7. Under this condition, the results of our solution reduce to those of the models for isothermal mass transfer in a laminar falling film (see, for example, ref. 5). Also, in this case there is no difference between the adiabatic and constant-temperature walls.

In addition to the results of this solution for the adiabatic and cunstant-temperaturc wall cases, Fig. 6 shows the results of the solution generated by Grigor'eva and Nakoryakov with the assumption of a uniform velocity profile (for a constant wall temperature only).13 Their solution shows the same initial and asymptotic behavior as the present one. 13 However, theirs underpredicts the length required to achieve a certain temperature or concentration level by about $40 \%$. 


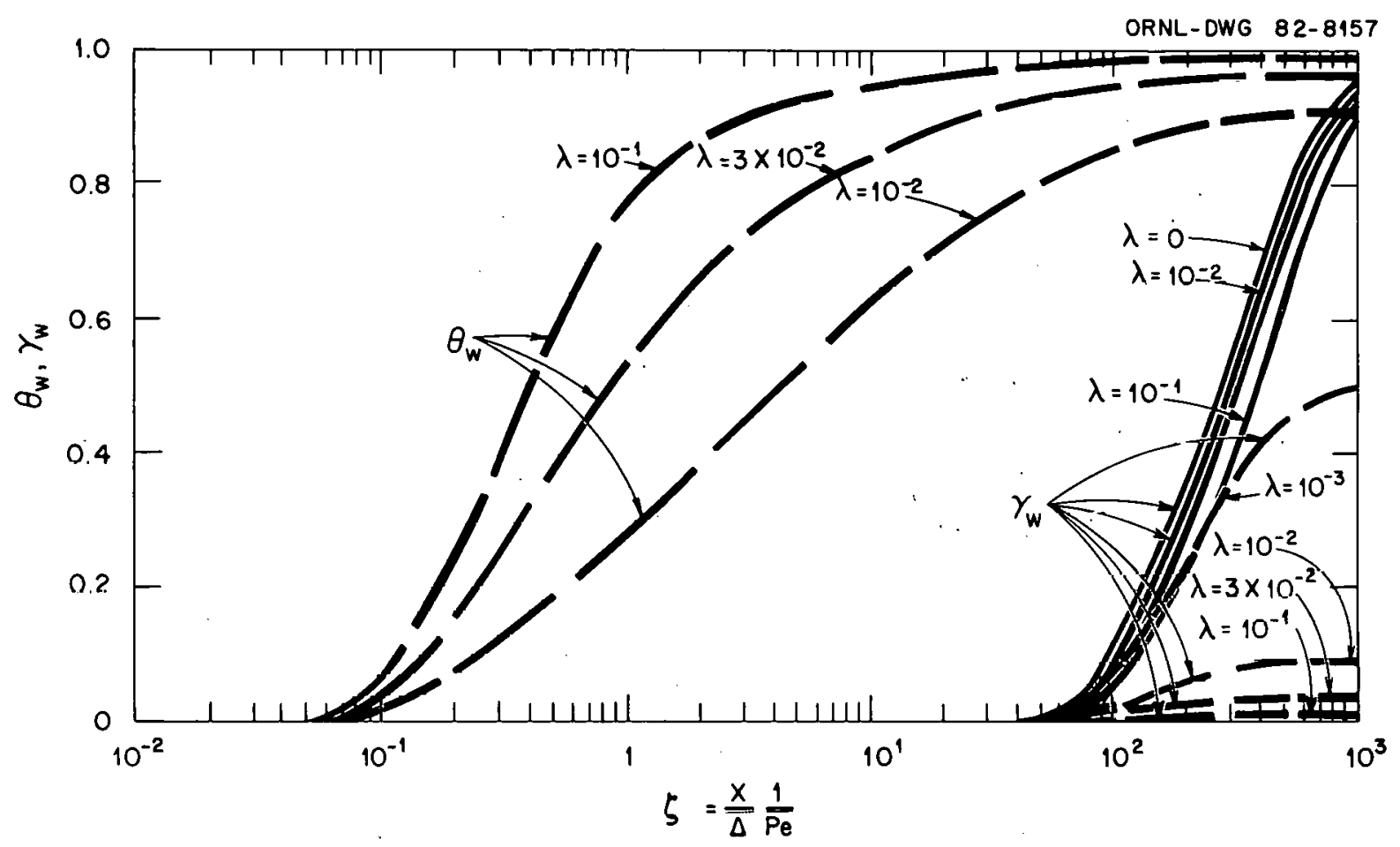

Fig. 7. Dimensionless wall temperature and concentration as functions of the normalized length $\zeta$ for Le $=0.001$ and different values of $\lambda$. Broken lines describe adiabatic wall; solid lines describe constanttempcrature wall.

The effect of the Lewi.s number is shown in Figs. 8 and 9, describing the temperature and concentration at the interface and at the wall, rcopectively. As in F1g. 6, each curve in Fig. 8 represents elther $\theta_{\text {i }}$ or $\gamma_{i}$. The initial and asymptotic behaviors are as predicted by the formulas given in Figs. 2 and 3. An increase in Le leads to a decrease in $\theta_{i}$ and to an increase in $\gamma_{i}$, at $\zeta=0$ for hoth rases and at $\zeta \rightarrow m$ for Llie adlabarlc wall case. In addition, Le has an effect on the development of the concentration boundary layer. The larger Le, the shorter the distance required for the concentration change to reach the wall, as shown by the curves for $\gamma_{w}$ in Fig. 9.

Figure 10 shows the mass flux at the interface, $\mu_{i}$, as a function of $\zeta$ for Le $=0.001$ and different values of $\lambda$. Under all conditions, the rate of absorption is lower for an adiabatic wall than for a constant-temperature wall. Initially, at small $\zeta$, the curves for the two cases coincide. For larger $\zeta$, after the thermal boundary layer has become fully developed, the heat removed at the wall enhances the mass 


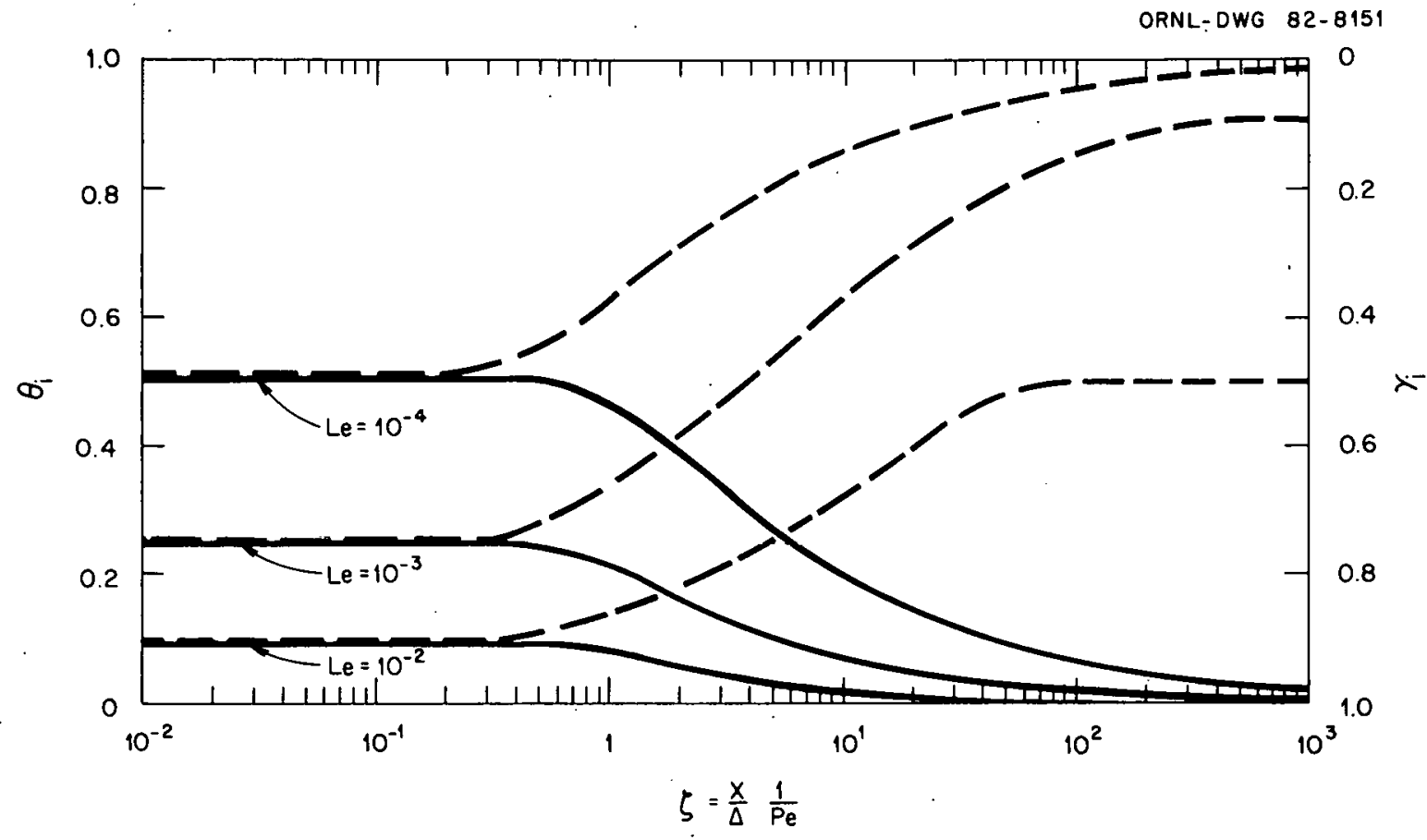

Fig. 8. Dimensionless interface temperature and concentration as functions of the normalized length $\zeta$ for $\lambda=0.01$ and different values of Le. Broken lines describe adiabatic wall; solid lines describe constanttemperature wall.

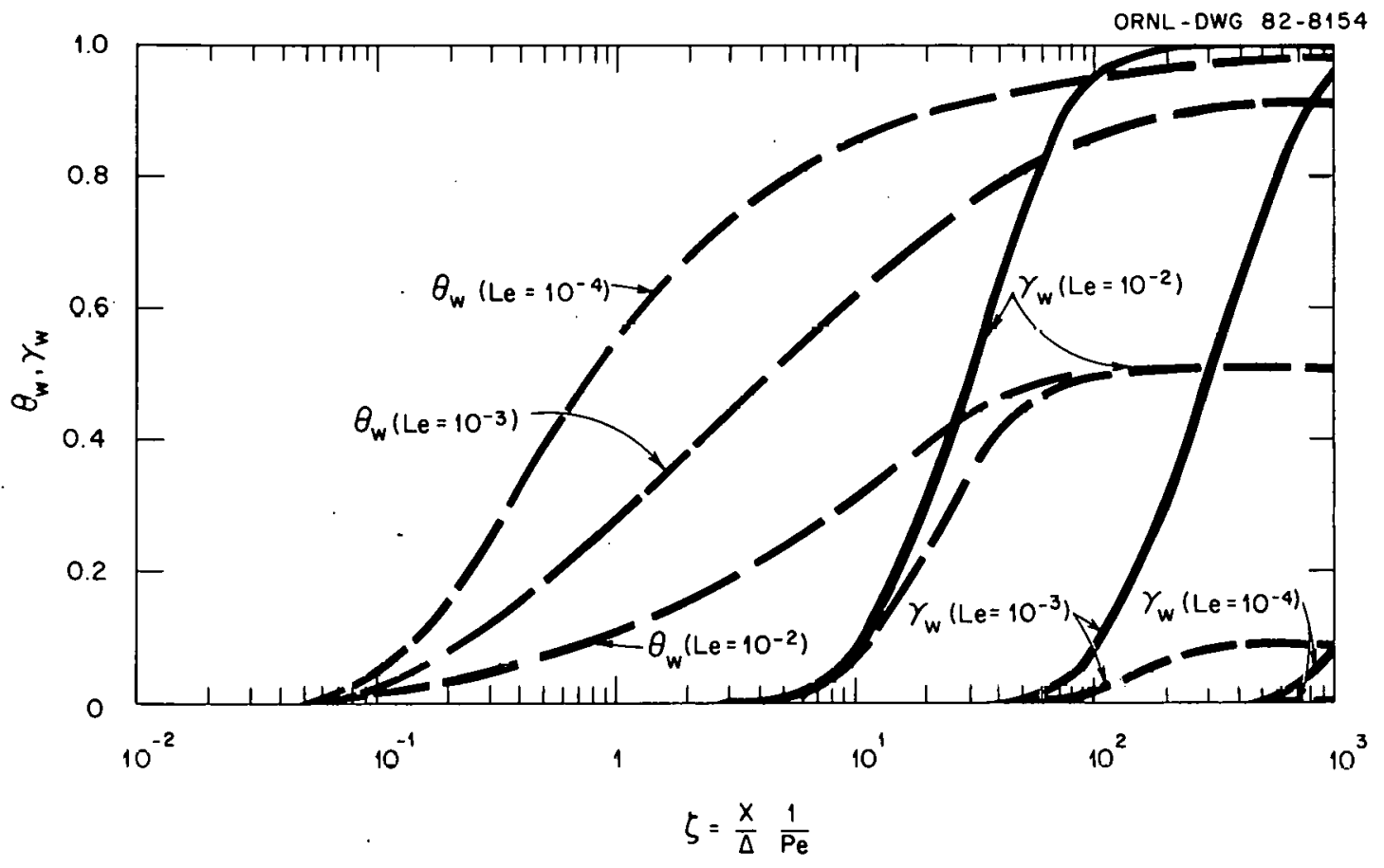

Fig. 9. Dimensionless wall temperature and concentration as functions of the normalized length $\zeta$ for $\lambda=0.01$ and different values of Le. Broken lines describe adiabatic wall; solid lines describe constanttemperature wall. 




Fig. 10. Dimensionless mass flux at the interface as a function of the normalized length $\zeta$ for Le $=0.001$ and different values of $\lambda$. Broken lines describe adiabatic wall; solid lines describe constanttemperature wall.

transfer in the constant-temperature wall case. The point at which the solid and broken curves part may serve as a measure for the length required for the full development of the thermal boundary layer. The value of $\mu_{1}$ tends to zern at large $\zeta$ for both cases. Alsu, illiciding $\lambda$ reduces the mass flux, as expected. The curve for $\lambda=0$ describes the case of isothermal mass transfer, in which $\mu_{i}$ is the largest possible value for the given Le, and where there is no difference between the adiabatic and constant-temperature walls. 


\section{HEAT AND MASS TRANSFER COEFFICIENTS}

The literature is often somewhat ambiguous about the definition of heat and mass transfer coefficients. This is particularly so in problems of simultaneous heat and mass transfer due to the coupling between the two processes. Yih and Seagrave have used two different definitions of the Sherwood number, one based on $\left(C_{i}-\bar{C}\right)$ and the other on $\left(C_{i}-C_{0}\right) .11$ Nakoryakov and Grigor'eva have defined it based on $\left(C_{0}-C_{e}\right) \cdot 14$ Tamir and Taitel have used an additional definition of an average Sherwood (or Nusselt) number based on a logarithmic mean concentration (or temperature) difference. ${ }^{5}$

We will define the transfer coefficients based on the quantity difference which constitutes the driving force for the transfer phenomenon. The coefficient of local mass transfer from the interface to the bulk of the liquid is defined through the Sherwood number as

$$
S h=\frac{h_{M}}{D}=\frac{\mu_{i}}{\left(\gamma_{i}-\bar{\gamma}\right)} \text {. }
$$

The coefficient of local heat transfer from the interface to the bulk of the liquid is defined through the Nusselt number as

$$
N u=\frac{h_{T}^{\Delta}}{k}=\frac{\mu_{i} \lambda}{\left(\theta_{i}-\dot{\theta}\right)} .
$$

In the constant-temperature wall case we must also consider the heat transfer coefficient from the bulk of the fluid to the wall. Hence,

$$
\mathrm{Nu}^{\prime}=\frac{\mathrm{h}_{\mathrm{T}}{ }^{\prime} \Delta}{\mathrm{k}}=\frac{\mathrm{q}_{\mathrm{w}}}{\bar{\theta}}
$$

Figure 11 describes the Sherwood number as a function of the normilized length $\zeta$ for different values of Le and $\lambda$. The value of $\mathrm{Sh}$ is very large for small $\zeta$ and decreases toward an asymptotic value as $\zeta$ increases. For each set of conditions, Sh is greater for a constanttemperature wall than for an adiabatic wall. The reasons are the same as those for $\mu_{i}$ (Fig. 10). The behavior in the two cases is the same 


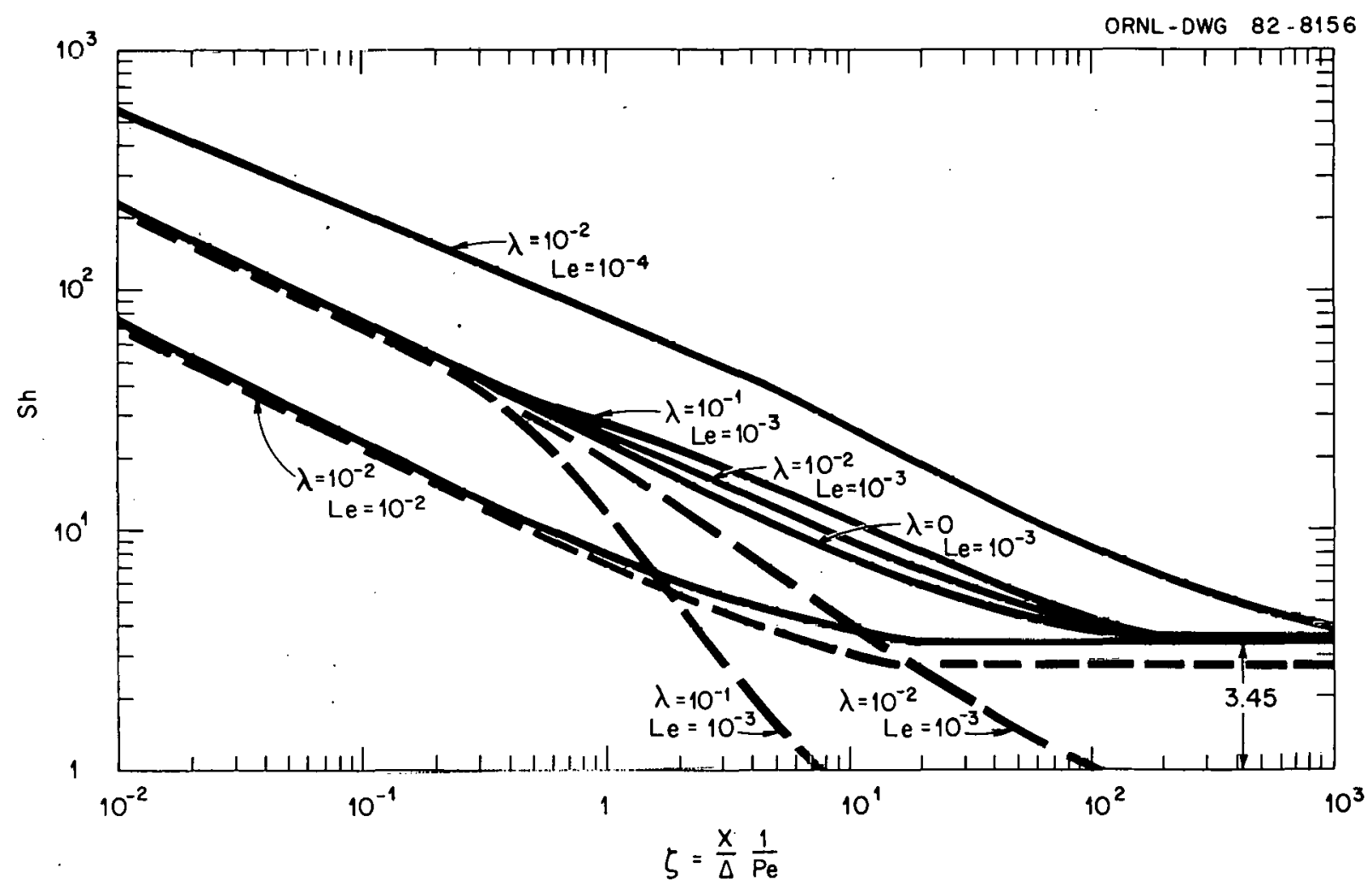

Fig. 1l. Local Sherwood number as a function of the normalized length $\zeta$ for different values of Le and $\lambda$. Broken lines describe adiabatic wall; solid lines describe conetunt-temperature wal1.

for small $\zeta$, and the discrepancy begins when the thermal boundary layer has reached the wall, increasing with $\zeta$.

In the case of a constant-temperature wall, the effect of $\lambda$ on Sh is small. For fixed $\lambda$, Sh is larger for smaller Le, contrary to what may be expected, because while the mass flux $\mu_{i}$ increases with Le, the driving force $\left(\gamma_{i}-\bar{\gamma}\right)$ increases even faster. A smaller Lewis number requires a larger distance for the concentration boundary layer to become fully developed. For all combinations of $\lambda$ and Le, the Sherwood number for a constant-temperature wall tends to an asymptotic value of 3.45 .

In the case of the adiabatic wall, increasing $\lambda$ reduces $S h$ significantly for all values of Le. A larger $\lambda$ leads to a greater deviation from the constant-temperature wall bchavior, this deviation shrinking to zero for $\lambda=0$. For fixed $\lambda$, a larger Lewis number results in a smaller deviation. Unlike the constant-temperature wall case, the asymptotic value of Sh depends on $\lambda$ and Le, decreasing with the former and increasing with the latter. 
The variations of $\mathrm{Nu}$ and $\mathrm{Nu}^{\prime}$ with $\zeta$ are illustrated in $\mathrm{Fig}, 12$ and are considerably less marked than that of $\mathrm{Sh}$. In the initial region of de-

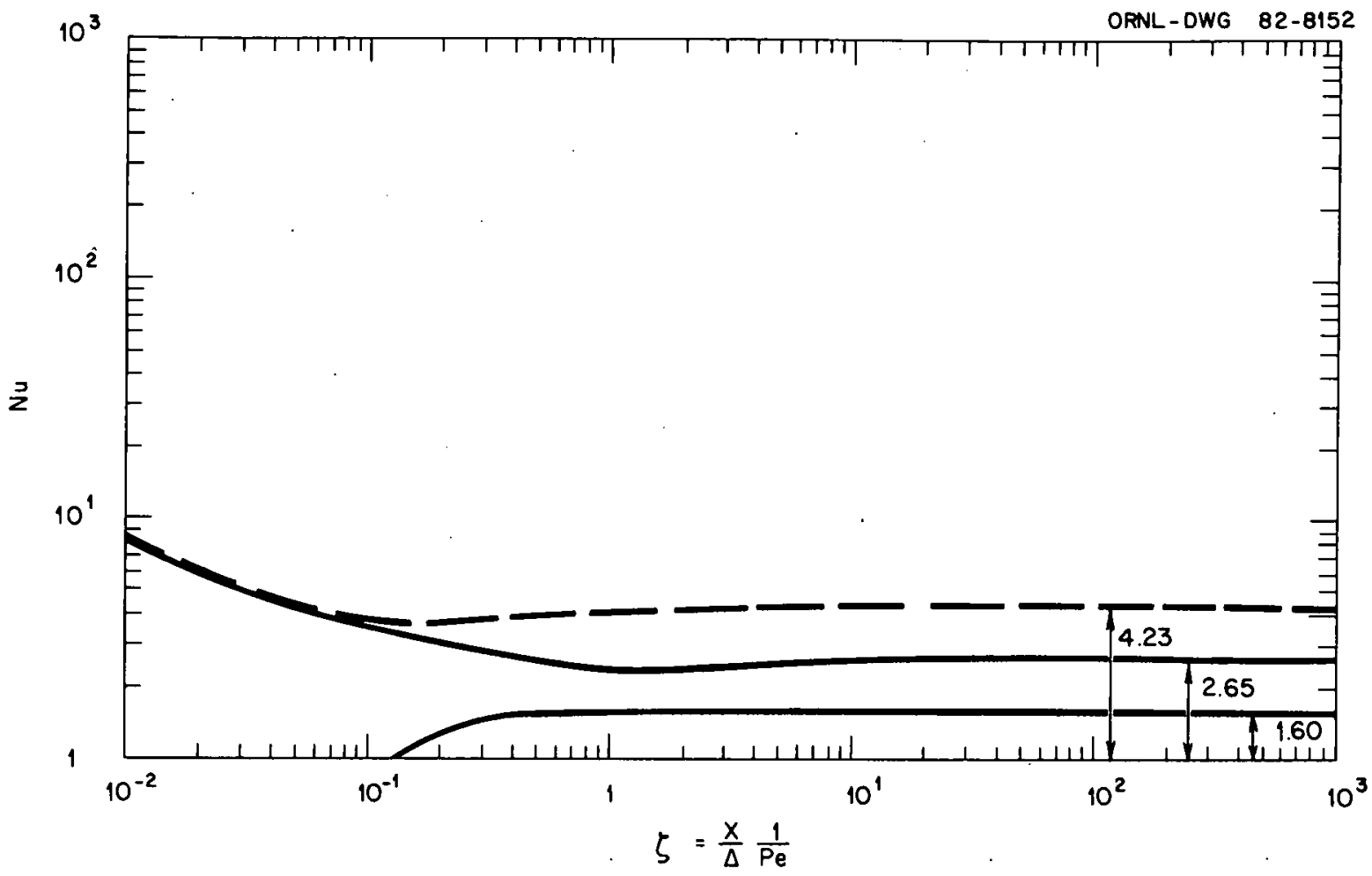

Fig. 12. Local Nusselt number as a function of the normalized length $\zeta$. The curves are almost unaffected by vaxiation in Le between $10^{-3}$ and $10^{-2}$ and by variations in $\lambda$ between $10^{-3}$ and $10^{-1}$. Broken lines describe adiabatic wall; solid lines describe constanttemperature wall.

velopment of the thermal boundary layer, $\mathrm{Nu}$ decreases in the same manner for the adiabatic and for the constant-temperature wall cases. In this region, $\mathrm{Nu}^{\prime}$ is zero, as the effects at the Interface have not reached the wall. Beyond that region there is little variation in $\mathrm{Nu}$, which tends to the asymptotic values of 4.23 and 2.65 for the adiabatic and constant-temperature wall, respectively. The asymptotic value of $\mathrm{Nu}^{\prime}$ reaches 1.60 . This behavior is almost unaffected by $\lambda$ and Le for a wide range of values of these parameters.

The results of the "slug flow" model by Grigor'eva and Nakoryakov show the same general behavior, but the actual values of the coefficients deviate by about $20 \%$ from those of the present analysis. ${ }^{13}$ With the assumption of a uniform velocity profile and a constant-temperature wall, the asymptotic value of $\mathrm{Sh}$ is 3.00 , and that of both $\mathrm{Nu}$ and $\mathrm{Nu}$ ' is 2.00 . 


\section{THIS PAGE}

\section{WAS INTENTIONALLY LEFT BLANK}




\section{INTEGRAL SOLUTION}

In addition to the exact solutions described in the previous sections, an approximate integral method was employed, and its results were compared with those of the former. The advantage of the integral method is its simplicity and the possibility of obtaining explicit formulas for most of the parameters of interest. Computing time was reduced significantly and the results agreed very well with the exact solutions.

The mathematical formulation of the integral solution and its results are described in this section. Readers uninterested in these details should skip to Sect. 8 .

\subsection{Formulation}

The integral method of solution converts the partial differential Eqs. (7) and (8) into ordinary ones by assuming the shape of the temperature and concentration profiles across the thin liquid film, based on the given boundary conditions. The exact shape of those profiles is not our primary interest; rather, it is important to learn about the variation with $\zeta$ of the temperature and concentration at the interface and at the wall, from which the heat and mass transfer coefficients can be calculated. When the profiles assumed satisfy the boundary conditions and are close in shape to the actual ones, the integral method gives results close to those of an exact solution, as has been demonstrated in many boundary layer problems as well as in a case similar to the present one of isothermal mass transfer in a falling film. 5

The integral form of Eqs. (7) and (8) is obtained by integration across the film thickness and making use of the conditions $(9 a-c)$ and $(10 \mathrm{a}-\mathrm{c})$. Energy $\mathrm{Eq}$. (7) hecomes

$$
\frac{d}{d \zeta} \int_{0}^{1 .} v \theta d \eta=\mu_{i} \lambda-q_{w},
$$

where $q_{w}$ is the dimensionless heat flux at the wall, $q_{w}=[\partial \theta / \partial \eta]_{\eta=0}$. The diffusion equation, Eq. (8), becomes 
$\frac{d}{d \zeta} \int_{0}^{1} v \gamma d n=L e \mu_{i}$.

Before proceeding with the formulation of temperature and concentration profiles, it would be useful to consider their qualitative behavior.

Figure 13 describes the variations in concentration and temperature for



(a)

(b)

Fig. 13. Qualitative distribution of the temperature and concentration in the falling film: (a) adiabatic wall and (b) constanttemperature wall. 
the two cases of interest - the constant-temperature wall and the adiabatic wall. The liquid at $\zeta=0$ is at a state of nonequilibrium with the vapor. As a result, a process of simultaneous heat and mass transfer begins at the interface and extends its effect gradually into the film. Thermal and concentration boundary layers begin to develop and grow in thickness until they fill the entire depth of the film. As will be shown later, the thermal boundary layer usually becomes fully developed first.

For both layers in this developing region, the temperatures and concentrations at the interface are functions of the boundary layer thickness, which is itself a function of $\zeta$. Once fully developed, the profiles continue to vary over the entire film thickness as long as the transfer process at the interface continues. After sufficient distance in the direction of flow, the temperature and concentration become uniform across the film as equilibrium is reached.

In accordance with the above, let us denote the value of $\zeta$ where the thermal and concentration boundary layers become fully developed by $\zeta_{\theta}$ and $\zeta_{\gamma}$, respectively. We will assume the following profiles, satisfying the boundary conditions $(9 b)$ and $(9 c)$ :

1. Concentration.

In the developing boundary layer region, $0 \leq \zeta \leq \zeta_{\gamma}$,

$$
\gamma=\left\{\begin{array}{l}
0 \quad \text { for } 0 \leq n \leq\left(1-\delta_{\gamma}\right) \\
\gamma_{i}\left[\left(1-\delta_{\gamma}-n\right) / \delta_{\gamma}\right]^{2} \quad \text { for }\left(1-\delta_{\gamma}\right) \leq n \leq 1
\end{array},\right.
$$

which also satisfies $\gamma=0$ and $\partial \gamma / \partial \eta=0$ at the edge of the boundary layer. The bulk concentration in this region would then be

$$
\bar{\gamma}=\int_{0}^{1} \operatorname{vrdn}=\frac{\gamma_{i}}{2}\left(\delta_{\gamma}-\frac{\delta_{\gamma}^{3}}{10}\right) \text {. }
$$

In the fully developed boundary layer region, $\zeta \geq \zeta_{\gamma}$,

$$
\gamma=\gamma_{w}+\left(\gamma_{i}-\gamma_{w}\right) n^{2}
$$


where $\gamma_{w}$ is the dimensionless concentration at the wall. The bulk concentration for this region becomes

$$
\bar{\gamma}=\int_{0}^{1} v \gamma d \eta=\frac{1}{20}\left(9 \gamma_{i}+11 \gamma_{w}\right) \text {. }
$$

Note that at the point of transition between the two regions, $\zeta=\zeta_{\gamma}$, where $\delta_{\gamma}=1$ and $\gamma_{w}=0$, we obtain $\gamma=\gamma_{i} n^{2}$ and $\bar{\gamma}=9 \gamma_{i} / 20$ from both Eqs. : $(43 a-b)$ and $(44 a-b)$.

\section{Temperature.}

In the developing boundary layer region, $0 \leq \zeta \leq \zeta_{\theta}$,

$$
\theta=\left\{\begin{array}{l}
0 \quad \text { for } 0 \leq n \leq\left(1-\delta_{\theta}\right) \\
\theta_{i}\left[\left(1-\delta_{\theta}-n\right) / \delta_{\theta}\right]^{2} \quad \text { for }\left(1-\delta_{\theta}\right) \leq n \leq 1
\end{array}\right. \text {, }
$$

with the bulk temperature

$$
\bar{\theta}=\int_{0}^{1} \mathrm{v} \theta \mathrm{d} n=\frac{\theta_{i}}{2}\left(\delta_{\theta}-\frac{\delta_{\theta}^{3}}{10}\right) .
$$

The same profiles apply in this region to both the adiabatic and constanttemperature wall cases.

In the fully developed boundary layer region, $\zeta \geq \zeta_{\theta}$, then for the adiabatic wall,

$$
\begin{aligned}
& \theta=\theta_{w}+\left(\theta_{j}-\theta_{w}\right) n^{2}, \\
& \bar{\theta}=\frac{1}{20}\left(9 \theta_{i}+11 \theta_{w}\right),
\end{aligned}
$$

where $\theta_{w}$ is the dimensionless temperature at the wa11. For the constanttemperature wall,

$$
\begin{aligned}
& \theta=q_{w} n+\left(\theta_{i}-q_{w}\right) n^{2}, \\
& \bar{\theta}=\frac{1}{40}\left(18 \theta_{i}+7 q_{w}\right),
\end{aligned}
$$


where $\mathrm{q}_{\mathrm{w}}$ is the dimensionless heat flux at the wall.

Note that at the point of transition between the two regions, $\zeta=\zeta_{\theta}$, where $\delta_{\theta}=1$ and $\theta_{w}=0$ or $q_{w}=0$ (for the adiabatic and constanttemperature wall, respectively), we obtain $\theta=\theta_{i} n^{2}$ and $\bar{\theta}=9 \theta_{i} / 20$ from both Eqs. $(45 a-b)$ and $(46 a-d)$.

Substitution of the above profiles in the integral Eqs. (41) and (42) yields

(1) Energy equation:

or

$$
\begin{aligned}
& \frac{\mathrm{d}}{\mathrm{d} \zeta}\left[\frac{\theta_{i}}{2}\left(\delta_{\theta}-\frac{\delta_{\theta}^{3}}{10}\right)\right]=\mu_{i} \lambda \quad \text { for } 0 \leq \zeta \leq \zeta_{\theta} ; \\
& \frac{\mathrm{d}}{\mathrm{d} \zeta}\left[\frac{1}{20}\left(9 \theta_{i}+11 \theta_{\mathrm{w}}\right)\right]=\mu_{i} \lambda \quad \text { for adiabatic wall, }
\end{aligned}
$$

$$
\left.\frac{\mathrm{d}}{\mathrm{d} \zeta}\left[\frac{1}{40}\left(18 \theta_{i}+7 \mathrm{q}_{\mathrm{w}}\right)\right]=\mu_{i} \lambda-\mathrm{q}_{\mathrm{w}} \quad \begin{array}{c}
\text { for constant-tem- } \\
\text { perature wall, }
\end{array}\right\}
$$

(2) Diffusion equation:

$$
\begin{aligned}
& \frac{\mathrm{d}}{\mathrm{d} \zeta}\left[\frac{\gamma_{i}}{2}\left(\delta_{\gamma}-\frac{\delta_{\theta}{ }^{3}}{10}\right)\right]=\operatorname{Le\mu }_{i} \quad \text { for } 0 \leq \zeta \leq \zeta_{\gamma}, \\
& \frac{\mathrm{d}}{\mathrm{d} \zeta}\left[\frac{1}{20}\left(9 \gamma_{i}+11 \gamma_{\mathrm{w}}\right)\right]=\mathrm{Le \mu}_{i} \quad \text { for } \zeta \geq \zeta_{\gamma} .
\end{aligned}
$$

Also, from Eq. (10b) and the concentration profile,

$$
\begin{aligned}
& \mu_{i}=2 \gamma_{i} / \delta_{\gamma} \text { for } 0 \leq \zeta \leq \zeta_{\gamma}, \\
& \mu_{i}=2\left(\gamma_{i}-\gamma_{w}\right) \quad \text { for } \zeta \geq \zeta_{\gamma},
\end{aligned}
$$

and from Eq. (10c) and the temperature profile,

$$
\begin{aligned}
& \mu_{i} \lambda=2 \theta_{i} / \delta_{\theta} \text { for } 0 \leq \zeta \leq \zeta_{\theta} ; \\
& \mu_{i} \lambda=2\left(\theta_{i}-\theta_{w}\right) \text { for } \zeta \geq \zeta_{\theta}, \text { adiabatic wall; } \\
& \mu_{i} \lambda=2 \theta_{i}-q_{w} \quad \text { for } \zeta \geq \zeta_{\theta}, \text { constant-temperature wall. }
\end{aligned}
$$


Equations $(47 a-c)$ and $(50 a-c)$. plus the equilibrium condition at the interface (10a) provide five equations for the five unknown variables of interest: $\theta_{i}, \gamma_{i}, \mu_{i}, \delta_{\gamma}$ alternating with $\gamma_{w}$, and $\delta_{\theta}$ alternating with $\theta_{w}$ for the adiabatic wall or with $q_{w}$ for the constant-temperature wall. All are functions of the single independent variable $\zeta$. The variable $\lambda$ may be expressed in terms of $\theta_{i}$ and $\gamma_{i}$ at each point. The boundary conditions are

$$
\delta_{0}=0 \text { and } \delta_{\gamma}=0 \text { at } \tau=0 \text {, }
$$

for the developing boundary layer regions, and

$$
\begin{aligned}
& \gamma_{w}=0 \quad \text { at } \zeta=\zeta_{\gamma} \text {, where } \delta_{\gamma}=1 \text {; } \\
& 0_{w}-0 \text { for adiabalic wa11, } \\
& \text { or } \\
& \mathrm{q}_{\mathrm{w}}=0 \text { for constant-temperature wal1, }
\end{aligned}
$$

for the fully developed regions.

\subsection{Solution}

Figure 13 describes three zones of the liquid film, indicated by numerals 1,2 , and 3 . In zone 1 both the thermal and concentration boundary layers are developing, in zone 2 one is fully developed and the other still developing, and in zone 3 both boundary layers are fully developed. Our solution will proceed from one zone to the next in that order.

\section{Zoule 1}

As is evident from Fig. 13, the behavior in this zone is the same for both the adiabatic and constant temperature wall cases. The equations in effect are (47a), (48a), (49a), (50a), and (17a), with the boundary 
condition (51a). Eliminating $\mu_{i}$ between Eqs. (47a) and (48a), integrating the resulting differential equation, and applying the boundary condition yields

$$
\frac{\mathrm{Le}}{\lambda} \theta_{i}\left(\delta_{\theta}-\frac{\delta_{\theta}^{3}}{10}\right)=\gamma_{i}\left(\delta_{\gamma}-\frac{\delta_{\gamma}^{3}}{10}\right) .
$$

Eliminating $\mu_{i}$ between Eqs. (49a) and (50a) gives

$$
\frac{\gamma_{i}}{\delta_{\gamma}}=\frac{1}{\lambda} \frac{\theta_{i}}{\delta_{\theta}}
$$

Combining Eqs. (52) and (53) results in

$$
\operatorname{Le} \delta_{\theta}^{2}\left(1-\frac{\delta_{\theta}^{2}}{10}\right)=\delta_{\gamma}^{2}\left(1-\frac{\delta^{2}}{10}\right) \text {. }
$$

Since $\delta_{\gamma}$ and $\delta_{\theta}$ are both less than or equal to unity, it is clear from Eq. (54) that the ratio $\delta_{\gamma} / \delta_{\theta}$ is of the order Le $e^{\frac{1}{2}}$. For most absorbent liquids the Lewis number is much smaller than one. It is therefore evident that the thermal boundary layer becomes fully developed when the concentration boundary layer is still quite thin. We thus find, from Eq. (54),

$$
\delta_{\gamma}=\sqrt{\operatorname{Le}} \delta_{\theta}\left(1-\frac{\delta_{\theta}^{2}}{10}\right)^{\frac{1}{2}},
$$

and in particular, $\delta_{\gamma}=\sqrt{9 \mathrm{Le} / 10}$ at $\zeta=\zeta_{\theta}$ where $\delta_{\theta}=1$. By suhatituting $\delta_{\gamma}$ from Eq. (55) into Eq. (53), and making use of Eq. (17a), we can express $\theta_{i}$ and $\dot{\gamma}_{i}$ in terms of $\delta_{\theta}$ :

$$
\begin{aligned}
\theta_{i}= & \frac{1}{1+\sqrt{\frac{L e}{\lambda}}\left(1-\frac{\delta_{\theta}^{2}}{10}\right)^{\frac{1}{2}}}, \\
\gamma_{i}= & \frac{\sqrt{\frac{L e}{\lambda}}\left(1-\frac{\delta_{\theta}^{2}}{10}\right)^{\frac{1}{2}} .}{1+\sqrt{\frac{L e}{\lambda}}\left(1-\frac{\delta_{\theta}^{2}}{10}\right)^{\frac{1}{2}}} .
\end{aligned}
$$


The bulk temperature and concentration from Eqs. (45b) and (43b) become

$$
\begin{aligned}
& \bar{\theta}=\frac{1}{2} \frac{\delta_{\theta}\left(1-\frac{\delta_{\theta}^{2}}{10}\right)}{1+\sqrt{\frac{L e}{\lambda}}\left(1-\frac{\delta_{\theta}^{2}}{10}\right)^{\frac{1}{2}}}, \\
& \bar{\gamma}=\frac{1}{2} \frac{\mathrm{Le}}{\lambda} \frac{\delta_{0}\left(1-\frac{\delta_{\theta}^{2}}{10}\right)}{1+\sqrt{\frac{L e}{\lambda}}\left(1-\frac{\delta_{\theta}^{2}}{10}\right)^{\frac{1}{2}}} .
\end{aligned}
$$

Now all the quantities of Incerest have been explessed in terms of $\delta_{\theta}$; it remains to determine how $\delta_{\theta}$ varies with $\zeta$. By substituting $\mu_{i} \lambda$ from Eq. (50a) into Eq. (47a) and $\theta_{i}$ from Eq. (56a) into the resulting equation, we obtain the following differential equation:

$$
\frac{\mathrm{d}}{\mathrm{d \zeta}}\left[\frac{\left(\delta_{\theta}-\frac{\delta_{\theta}^{3}}{10}\right)}{1+\sqrt{\frac{L e}{\lambda}}\left(1-\frac{\delta_{\theta}^{2}}{10}\right)^{\frac{1}{2}}}\right]=\frac{4}{\delta_{\theta}\left[1+\sqrt{\frac{L e}{\lambda}}\left(1-\frac{\delta_{\theta}^{2}}{10}\right)^{\frac{1}{2}}\right]},
$$

which may be integrated, using büundary condllluil (Jlu) Lu deter.. mine the constant of integration. Since $\delta_{\theta} \leq 1$, the resulting expression may be given a somewhat simplified approximate form, by expanding in terms of the small quantity $\left(\delta_{\theta}^{2} / 10\right)$ and neglecting high powers of it:

$$
\zeta=\frac{\delta_{\theta}^{\prime}}{8}\left[1-\frac{\varepsilon_{\theta}^{2}}{10}\left(\frac{1+(3 / 2) \lambda / L e}{1+\lambda / L \epsilon}\right)\right] .
$$

The point where the thermal boundary layer becomes fully developed is found by substituting $\delta_{\theta}=1$ into Eq. (58a):

$$
\zeta_{\theta}=\frac{9}{80}\left[\frac{1+(17 / 18) \lambda / \text { Le }}{1+\lambda / \text { Le }}\right] \text {. }
$$


Zone 2

Although in zone 1 the behavior was the same for the adiabatic and the constant-temperature wall, here a distinction must be made between them.

Adiabatic wall. The equations in effect are (47b), (48a), (49a), $(50 b)$, and (17a), with the boundary condition (5lc). Eliminating $\mu_{i}$ between Eqs. (47b) and (48a), integrating the resulting differential equation, and applying the boundary condition, yields

$$
\frac{1}{10}\left(9 \theta_{i}+11 \theta_{w}\right) \frac{L e}{\lambda}=\left(\delta \delta_{\gamma}-\frac{\delta^{3}}{10}\right) \gamma_{i} \text {. }
$$

Eliminating $\mu_{i}$ between Eqs. (49a) and (50b) gives

$$
\left(\theta_{i}-\theta_{w}\right)=\lambda \frac{\gamma_{i}}{\delta_{\gamma}^{\prime}} .
$$

Eliminating $\theta_{\mathrm{w}}$ between Eqs. (59) and (60) provides a relation between $\theta_{i}, \gamma_{i}$, and $\delta_{\gamma}$ which, together with Eq. (17a), yields

$$
\theta_{i}=\frac{\frac{\lambda}{2 \delta_{\gamma}}\left[\frac{11}{10}+\frac{\delta_{\gamma}^{2}}{L e}\left(1-\frac{\delta^{2}}{10}\right)\right]}{1+\frac{\lambda}{2 \delta_{\gamma}}\left[\frac{11}{10}+\frac{\delta_{\gamma}^{2}}{L e}\left(1-\frac{\delta_{\gamma}^{2}}{10}\right)\right]},
$$

The term $\theta_{w}$ can now be found from Eq. (60):

$$
\theta_{W}=\frac{\frac{\lambda}{2 \delta_{\gamma}}\left[-\frac{9}{10}+\frac{\delta^{2}}{\mathrm{Le}}\left(1-\frac{\delta^{2}}{10}\right)\right]}{1+\frac{\lambda}{2 \delta_{\gamma}}\left[\frac{11}{10}+\frac{\delta_{\gamma}^{2}}{\mathrm{Le}}\left(1-\frac{\delta_{\gamma}^{2}}{10}\right)\right]} .
$$


The bulk temperature and concentration from Eqs. (46B) and (43b) become

$$
\begin{aligned}
& \bar{\theta}=\frac{\lambda}{2 L e} \frac{\delta_{\gamma}\left(1-\frac{\delta^{2}}{10}\right)}{1+\frac{\lambda}{2 \delta} \cdot\left[\frac{11}{10}+\frac{\delta_{\gamma}^{2}}{L e}\left(1-\frac{\delta^{2}}{10}\right)\right]}, \\
& \bar{\gamma}=\frac{1}{2} \frac{\delta_{\gamma}\left(1-\frac{\delta_{\gamma}^{2}}{10}\right)}{1+\frac{\lambda}{2 \delta_{\gamma}}\left[\frac{11}{10}+\frac{\delta^{2}}{L e}\left(1-\frac{\delta^{2}}{10}\right)\right]} \text {. }
\end{aligned}
$$

Al1 the quantities of interest have now been expressed in terms of $\delta_{\gamma}$. To find the variation of $\delta_{\gamma}$ with $\zeta$, we substitute $\mu_{i} \lambda$ from

Eq. (50b) in Eq. (47b) and $\theta_{i}$ and $\theta_{w}$ from Eqs. (61a) and (61c) in the resulting equation:

$$
\begin{aligned}
& \frac{\mathrm{d}}{\mathrm{d} \zeta}\left\{\frac{\delta_{\gamma}{ }^{2}\left(1-\frac{\delta_{\gamma}{ }^{2}}{10}\right)}{\delta_{\gamma}+\frac{\lambda}{2}\left[\frac{11}{10}+\frac{\delta_{\gamma}{ }^{2}}{\mathrm{Le}}\left(1-\frac{\delta_{\gamma}{ }^{2}}{10}\right)\right]}\right\} \\
& =4 \operatorname{Le}\left\{\frac{\left.\left.1-\frac{\delta_{\gamma}{ }^{2}}{10}\right)\right]}{\delta_{\gamma}+\frac{\lambda}{2}\left[\frac{11}{10}+\frac{\delta_{\gamma}{ }^{2}}{\mathrm{Le}}\left(1-\frac{1}{10}\right)\right.},\right.
\end{aligned}
$$

which may be rewritten as

$$
\left\{\frac{\delta_{\gamma}\left(1-\frac{3 \delta_{\gamma}^{2}}{10}\right)+\frac{11}{10} \lambda\left(1-\frac{\delta_{\gamma}^{2}}{5}\right)}{1+\frac{\lambda}{2 \delta_{\gamma}}\left[\frac{11}{10}+\frac{\delta_{\gamma}^{2}}{\mathrm{Le}}\left(1-\frac{\delta^{2}}{10}\right)\right]}\right\} \frac{\mathrm{d} \delta_{\gamma}}{4 \mathrm{Le}}=\mathrm{d} \zeta_{2} .
$$


Equation (62b) may be integrated numerically as $\delta_{\gamma}$ varies from $\sqrt{9 \mathrm{Le} / 10}$ to 1 , and $\zeta$ varies correspondingly from $\zeta_{\theta}$ to $\zeta_{\gamma^{\circ}}$ An adaptive quadrature method was used in the above integration. 18

Constant temperature wall. The equations in effect are $(47 \mathrm{c})$, $(48 a),(49 a),(50 c)$, and (17a), with the boundary condition (51c). Elim- ination of $\mu_{i}$ and $\theta_{i}$ from Eqs. (49a), (50c), and (17a) provides an expression for $\mathrm{q}_{\mathrm{w}}$ :

$$
q_{w}=2\left(1-\gamma_{i}-\lambda \frac{\gamma_{i}}{\delta_{\gamma}}\right) \text {. }
$$

Substitution of $\mu_{i} \lambda$ from Eq. (50c), $q_{w}$ from Eq. (63), and $\theta_{i}$ from Eq. (17a) into Eq. (47c) gives

$$
\mathrm{d}\left(16 \gamma_{i}+7 \lambda \frac{\gamma_{i}}{\delta_{\gamma}}\right)=40\left(1-\gamma_{i}-2 \lambda \frac{\gamma_{i}}{\delta_{\gamma}}\right) \mathrm{d} \zeta
$$

Also, substitution of $\mu_{i}$ from Eq. (49a) into Eq. (48a) yields

$$
d\left[\gamma_{i}\left(\delta_{\gamma}-\frac{\delta^{3}}{10}\right)\right]=4 \mathrm{Le} \frac{\gamma_{i}}{\delta_{\gamma}} \mathrm{d} \zeta
$$

and elimination of $\zeta$ between Eqs. (64) and (65) results in a differential equation relating $\gamma_{i}$ to $\delta_{\gamma}$ :

$$
\frac{d\left[16 \gamma_{i}+7 \lambda\left(\gamma_{i} / \delta_{\gamma}\right)\right]}{\left[1-\gamma_{i}-2 \lambda\left(\gamma_{i} / \delta_{\gamma}\right)\right]}=\frac{10}{L e} \frac{d\left[\gamma_{i}\left(\delta_{\gamma}-\delta_{\gamma}^{3 / 10)}\right]\right.}{\left(\gamma_{i} / \delta_{\gamma}\right)},
$$

which may be rewritten as

$$
\frac{d \gamma_{i}}{d \delta_{\gamma}}=\frac{\gamma_{i}}{\delta_{\gamma}} \frac{7 \lambda-(10 / \text { Le })\left(\delta_{\gamma}+2 \lambda-\delta_{\gamma} / \gamma_{i}\right)\left(1-3 \delta_{\gamma}{ }^{2 / 10}\right) \delta_{\gamma}{ }^{2}}{\left(7 \lambda+16 \delta_{\gamma}\right)+(10 / L e)\left(\delta_{\gamma}+2 \lambda-\delta_{\gamma} / \gamma_{i}\right)\left(1-\delta_{\gamma}{ }^{2 / 10}\right) \delta_{\gamma}{ }^{2}} .
$$


Equation (66a) may be integrated with the boundary condition originating from (56b):

$$
\gamma_{i}=\frac{\sqrt{9 \mathrm{Le} / 10}}{\lambda+\sqrt{9 \mathrm{Le} / 10}} \text { at } \delta_{\gamma}=\sqrt{9 \mathrm{Le} / 10}
$$

where $\zeta=\zeta_{\theta}$. Once $\gamma_{i}$ has been found in terms of $\delta_{\gamma}, \theta_{i}$ and $q_{w}$ may be expressed in terms of $\delta_{\gamma}$ by means of Eqs. (17a) and (63). The bulk temperature and concentration $\bar{\theta}$ and $\bar{\gamma}$ may be determined from Eqs. (46d) and $(43 \mathrm{~b})$, respectively. It remains to determine how $\delta_{\gamma}$ varies with $\zeta$. An equation relating these two may be obtained by combining Eqs. ( 655$)$ and $(66 b)$ :

$$
\frac{\mathrm{d} \zeta}{\mathrm{d} \delta_{\gamma}}=\frac{1}{2} \frac{7 \lambda \delta_{\gamma}\left(1-\delta_{\gamma}{ }^{2} / 5\right)+8 \delta_{\gamma}{ }^{2}\left(1-3 \delta_{\gamma}{ }^{2} / 10\right)}{\left(7 \lambda+16 \delta_{\gamma}\right) \mathrm{Le}+10 \delta_{\gamma}{ }^{2}\left(\delta_{\gamma}+2 \lambda-\delta_{\gamma} / \gamma_{i}\right)\left(1-\delta_{\gamma}{ }^{2} / 10\right)} .
$$

Equations (66b) and (68) were integrated simultaneously using a fourthorder Runge-Kutta method. 18 The value of $\zeta$ where $\delta_{\gamma}$ becomes equal to unity marks the end of zone 2 .

\section{Zone 3}

In this zone both boundary layers are fully developed. Again, a distinction must be made between the adiabatic and constant-temperature wall cases.

Adiabatic wall. The equations in effect are (47b), (48b), (49b), (50b), and (17a), with the boundary condition (51c). Eliminating $\mu_{i}$ between Eqs. (47b) and (48b), integrating the resulting equation, and applying the boundary condition, yields

$$
\left(9 \theta_{i}+11 \theta_{w}\right)=\frac{\lambda}{L e}\left(9 \gamma_{i}+11 \gamma_{w}\right)
$$

Eliminating $\mu_{i}$ between Eqs. (49b) and (50b) gives

$$
\left(\theta_{i}-\theta_{w}\right)=\lambda\left(\gamma_{i}-\gamma_{w}\right)
$$


Equations (69), (70), and (17a) may be combined to express $\gamma_{i}, \theta_{i}$, and $\theta_{\mathrm{w}}$ in terms of $\gamma_{\mathrm{w}}$ as follows:

$$
\begin{aligned}
& \gamma_{i}=\frac{1-(11 / 20)(\lambda / \text { Le }) \gamma_{w}}{1+(9 / 20)(\lambda / L e)}, \\
& \theta_{i}=\frac{\lambda}{\operatorname{Le}} \frac{(9 / 20)+(11 / 20) \gamma_{w}}{1+(9 / 20)(\lambda / L e)}, \\
& \theta_{w}=\theta_{1}-\lambda \frac{1-\gamma_{w}-(\lambda / L e) \gamma_{w}}{1+(9 / 20)(\lambda / L e)} .
\end{aligned}
$$

Here, terms of the order Le have been neglected with respect to unity. Note that $\theta_{i}$ and $\theta_{w}$ are very close to each other; the difference between them is of relative order Le. The bulk temperature and concentration from Eqs. (46b) and (44b) become

$$
\begin{aligned}
& \bar{\theta}=\frac{\lambda}{\mathrm{Le}} \frac{(9 / 20)+(11 / 20) \gamma_{\mathrm{w}}+(11 / 20) \lambda \gamma_{\mathrm{w}}}{1+(9 / 20)(\lambda / \mathrm{Le})}, \\
& \bar{\gamma}=\frac{(9 / 20)+(11 / 20) \gamma_{\mathrm{W}}+(11 / 20) \lambda \gamma_{\mathrm{w}}}{1+(9 / 20)(\lambda / \mathrm{Le})} .
\end{aligned}
$$

Now all the quantities of interest have been expressed in terms of the dimensionless concentration at the wall, $\gamma_{w^{*}}$ It remains to find how $\gamma_{w}$ varies with $\zeta$. Substituting $\mu_{i}$ from Eq. (49b) into Eq. (48b) and $\gamma_{i}$ from Eq. (71a) into the resulting equation yields

$$
\frac{\mathrm{d}}{\mathrm{d} \zeta}\left[\frac{9}{20}+\frac{11}{20}(1+\lambda) \gamma_{\mathrm{w}}\right]=2 \mathrm{Le}\left[1-\gamma_{\mathrm{w}}-\frac{\lambda}{\mathrm{Le}} \gamma_{\mathrm{w}}\right] \text {, }
$$

which may be integrated with the boundary conditions (51c) to give

$$
\gamma_{w}=\left(\frac{L e}{L e+\lambda}\right)\left\{1-\exp \left[-\frac{40}{1 I}\left(\frac{L e+\lambda}{1+\lambda}\right)\left(\zeta-\zeta_{\gamma}\right)\right]\right\} .
$$

Constant temperature wall. The equations in effect are (47c), $(48 b),(49 b),(50 c)$, and $(17 a)$, with the boundary condition (51c). 
Eliminating $\mu_{i}$ and $\theta_{i}$ between Eqs. (49b), (50c), and (17a) provides an expression for $\mathrm{q}_{\mathrm{w}}$ :

$$
q_{w}=2\left[1+\lambda \gamma_{w}-(1+\lambda) \gamma_{i}\right]
$$

Substitution of $\mu_{i} \lambda$ from Eq. (50c), $q_{w}$ from Eq. (74), and $\theta_{i}$ from $\mathrm{Eq} \cdot(17 \mathrm{a})$ into Eq. (47c) gives

$$
(16+7 \lambda) d \gamma_{i}-7 \lambda d \gamma_{w}=10\left[\left(1-\gamma_{1}\right)+2 \lambda\left(\gamma_{w}-\gamma_{i}\right)\right] d_{\zeta} .
$$

Also, substitution of $\mu_{i}$ from Eq. (49b) into Eq. (48b) yields

$$
9 \mathrm{~d} \gamma_{i}+11 d \gamma_{w}=40 \operatorname{Le}\left(\gamma_{i}-\gamma_{w}\right) d \zeta
$$

Eliminating d $\zeta$ between Eqs. (75) and (76) results in a differential equation relating $\gamma_{i}$ to $\gamma_{w}$ :

$$
\frac{(16+7 \lambda) \mathrm{d} \gamma_{i}-7 \lambda \mathrm{d} \gamma_{w}}{\left(1-\gamma_{1}\right)+2 \lambda\left(\gamma_{w}-\gamma_{i}\right)}=\frac{9 \mathrm{~d} \gamma_{1}+11 \mathrm{~d} \gamma_{w}}{\operatorname{Le}\left(\gamma_{i}-\gamma_{w}\right)},
$$

which may be integrated with the boundary condition at $\zeta=\zeta_{\gamma}$ (where $\gamma_{w}=0$ and $\gamma_{i}=\gamma_{i}^{\prime}$ as obtained from the solution for zone 2 ), yielding

$$
\left[\frac{\left(1-\gamma_{i}\right)-2 \lambda\left(\gamma_{i}-\gamma_{w}\right)}{\left(1-\gamma_{i}^{\prime}\right)-2 \lambda \gamma_{i}^{\prime}}\right]=\left[\frac{1-\left(9 \gamma_{i}+11 \gamma_{w}\right) / 20}{1-9 \gamma_{i}{ }^{\prime} / 20}\right]\left(\frac{11 / 40 \lambda}{16 \text { Le }}\right) .
$$

The term in the brackets on the right-hand side of Eq. (78) is also equal to $(1-\bar{\gamma}) /\left(1-\bar{\gamma}^{\prime}\right)$. It is a number smaller than unity, taken to a very large power due to Le $\ll 1$. It can be shown that this results in

$$
1-\gamma_{i}-2 \lambda\left(\gamma_{i}-\gamma_{w}\right)=0(L e) \simeq 0 \text {; }
$$
hence,

$$
\gamma_{i}=\left(1+2 \lambda \gamma_{w}\right) /(1+2 \lambda)
$$

from Eq. (17a),

$$
\theta_{i}=2 \lambda\left(1-\gamma_{w}\right) /(1+2 \lambda) ;
$$


from Eq. (74);

$$
q_{w}=2 \lambda\left(1-\gamma_{w}\right) /(1+2 \lambda)
$$

The bulk temperature and concentration, $\bar{\theta}$ and $\bar{\gamma}$, may be determined from Eqs. (46d) and (44b), respectively:

$$
\begin{aligned}
& \bar{\theta}=(5 / 4) \lambda\left(1-\gamma_{\mathrm{w}}\right) /(1+2 \lambda) ; \\
& \bar{\gamma}=(1 / 20)\left(9+11 \gamma_{\mathrm{w}}+40 \lambda \gamma_{\mathrm{w}}\right) /(1+2 \lambda) .
\end{aligned}
$$

It remains to determine how $\gamma_{w}$ varies with $\zeta$. Substituting $\gamma_{i}$ from Eq. (79b) into Eq. (76) yields

$$
\frac{d \gamma_{w}}{\left(1-\gamma_{w}\right)}=\frac{40}{(11+40 \lambda)} \text { Le } d \zeta \text {, }
$$

which may be integrated with the boundary condition (51b) to give

$$
\gamma_{w}=1-\exp \left[-\left(\frac{40}{11+40 \lambda}\right) \operatorname{Le}\left(\zeta-\zeta_{\gamma}\right)\right] \text {. }
$$

\subsection{Results}

Figure 14 describes the main system's parameters as they vary through the three different zones for a typical set of values of Le and $\lambda$. The dimensionless boundary layer thickness, temperature, concentration, and heat and mass flux are shown as functions of the normalized length $\zeta$. Due to the largely different lengths of the three zones, a logarithmic scale has been chosen for $\zeta$, with a small linear portion near the inlet end. As in the results of the exact solutions, the solid lines describe the results for the constant temperature wall and the broken lines for the adiabatic wall case.

In zone 1 , the behavior is the same for the adiabatic and constanttemperature wall cases. The thermal boundary layer develops from zero to its full thickness while the concentration boundary layer develops partially to a normalized thickness $\sqrt{9 \mathrm{Le} / 10}$ at the end of the zone. The interface temperature and concentration are essentially constant at 

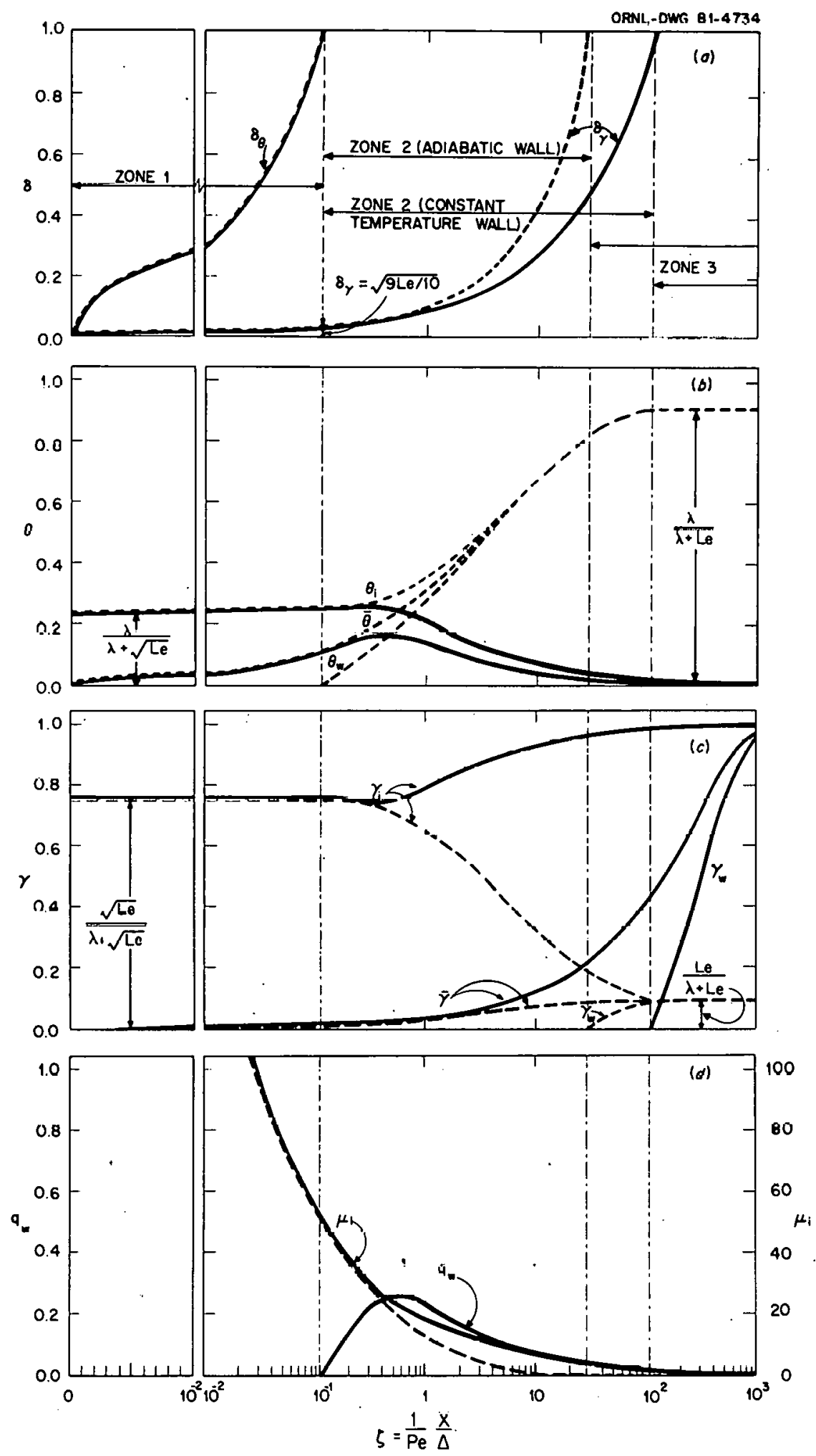

Fig. 14. Main dimensionless system parameters as functions of the normalized length $\zeta$ for Le 0.001 and $\lambda=0.01$ : (a) boundary layer thicknesses, (b) temperatures, (c) concentrations, and (d) heat and mass fluxes. Broken lines describe adiabatic wall; solid lines describe constant-temperature wall. 
the value reached initially at $\zeta=0$ upon contact with the vapor $[\lambda /(\lambda+\sqrt{L e})$ and $L e /(\lambda+\sqrt{L e})$, respectively $]$. The wall temperature and concentration are zero. The bulk temperature and concentration are close to zero and increasing. There is no heat flux through the wall; however, the mass flux $\mu_{i}$ in this zone is quite high, as the driving force for mass transfer is at its maximum. The length of zone 1 is given by Eq. (58b). It is almost constant at $\zeta_{\theta}=9 / 80$, decreasing slightly with $\lambda / \sqrt{\mathrm{Le}}$.

In zone 2 the concentration boundary layer reaches its full thickness, becoming fully developed after a shorter distance from the inlet in the adiabatic than in the constant-temperature wall case. In the former case, the wall, bulk, and interface temperatures increase monotonically toward a final common value and become close to each other at the end of the zone. This steady increase occurs because the heat of absorption is not being removed. For the constant-temperature wall, the interface and bulk temperatures increase slightly, following the trend of zone 1 , then decrease toward zero as heat flows out of the system.

The heat flux $\mathrm{q}_{\mathrm{w}}$ in this case begins at zero value at $\zeta=\zeta_{\theta}$, increases and reaches a maximum as more heat of absorption is created, and then decreases toward zero and has a low value of $2 \lambda /(1+2 \lambda)$ at the end of the zone. The interfacial concentration in both cases follows a trend opposite to that of the interfacial temperature, since $\gamma_{i}=1-\theta_{i}$ [Eq. (17a)]. The bulk concentration increases in both cases toward a final value equal to that of $\gamma_{i}$.

In zone 3 both boundary layers are fully developed. External heat and mass fluxes are small and changes in the temperature and concentration profiles take place by virtue of thermal and mass diffusion within the film, tending to make those profiles uniform. The temperature and concentration tend toward an asymptotic value, which may be found by substituting $\zeta \rightarrow \infty$ in the results of the solution for zone 3 . In the constant-temperature wall case, the dimensionless temperature becomes equal to that of the wall $(\theta=0)$ and the concentration reaches the corresponding equilibrium value $(\gamma=1)$. In the adiabatic wall case the asymptotic temperature reflects some increase from the initial value $[\theta=\lambda /($ Le $+\lambda)]$, and the corresponding equilibrium concentration 
$[\gamma=\mathrm{Le} /(\lambda+\mathrm{Le})]$ is lower than the thermodynamically possible value of 1 . The results of the integral solution were found to be in very good agreement with those of the exact solutions described earlier. 


\section{NUMERICAL EXAMPLE}

The following example will illustrate the use of the results obtained earlier for calculating the parameters in a practical case. Consider a film of $\mathrm{LiBr}-\mathrm{H}_{2} \mathrm{O}$ solution flowing down over a tray inclined at $45^{\circ}$, at a mass flow rate of $0.25 \mathrm{~kg} / \mathrm{s}$ per meter of breadth. The initial temperature and concentration of the solution are $75^{\circ} \mathrm{C}$ and $60 \%$ LiBr by weight, respectively. The film is in contact with dry saturated water vapor at $45^{\circ} \mathrm{C}$ which has a vapor pressure higher than that of the solution at the above conditions and is therefore being absorbed. We would like to calculate (1) the maximum change in solution concentration achievable when the tray is adiabatic, (2) the same when the tray is being cooled from below and kept at a constant temperature, (3) the maximum temperature rise of the solution in the adiabatic case, and (4) the length of tray required, in the direction of flow, to produce $90 \%$ of the maximum concentration change in either case.

The absorption process is described on a thermodynamic equilibrium chart (taken from ref. 19) in Fig. 15 for both the adiabatic and constanttemperature cases. The solution at its initial state has a vapor pressure of $4.8 \mathrm{kPa}$, considerably lower than that of the vapor at $45^{\circ} \mathrm{C}(9.7 \mathrm{kPa})$. In the case of the adiabatic wall, the water concentration in the absorbent increases ( $\mathrm{LiBr}$ decreases) and the bulk temperature increases. For the constant-temperature wall, the bulk temperature is the same at the beginning and end of the process; however, in between there is some increase in temperature, as illustrated in Fig. 2.

We will begin by calculating the flow velocity and film thickness. The physical properties of $\mathrm{LiBr}-\mathrm{H}_{2} \mathrm{O}$ solution under the present temperature and concentration are listed in Table 2. The film Reynolds number is given by ref. 1 :

$$
\operatorname{Re}=4 \Gamma / \mu=\frac{4 \times 0.25}{3 \times 10^{-3}}=333
$$

The flow is, therefore, clearly laminar ( $\operatorname{Re}<500)$. Then, from the Nusselt formula for falling films: ${ }^{1}$ 


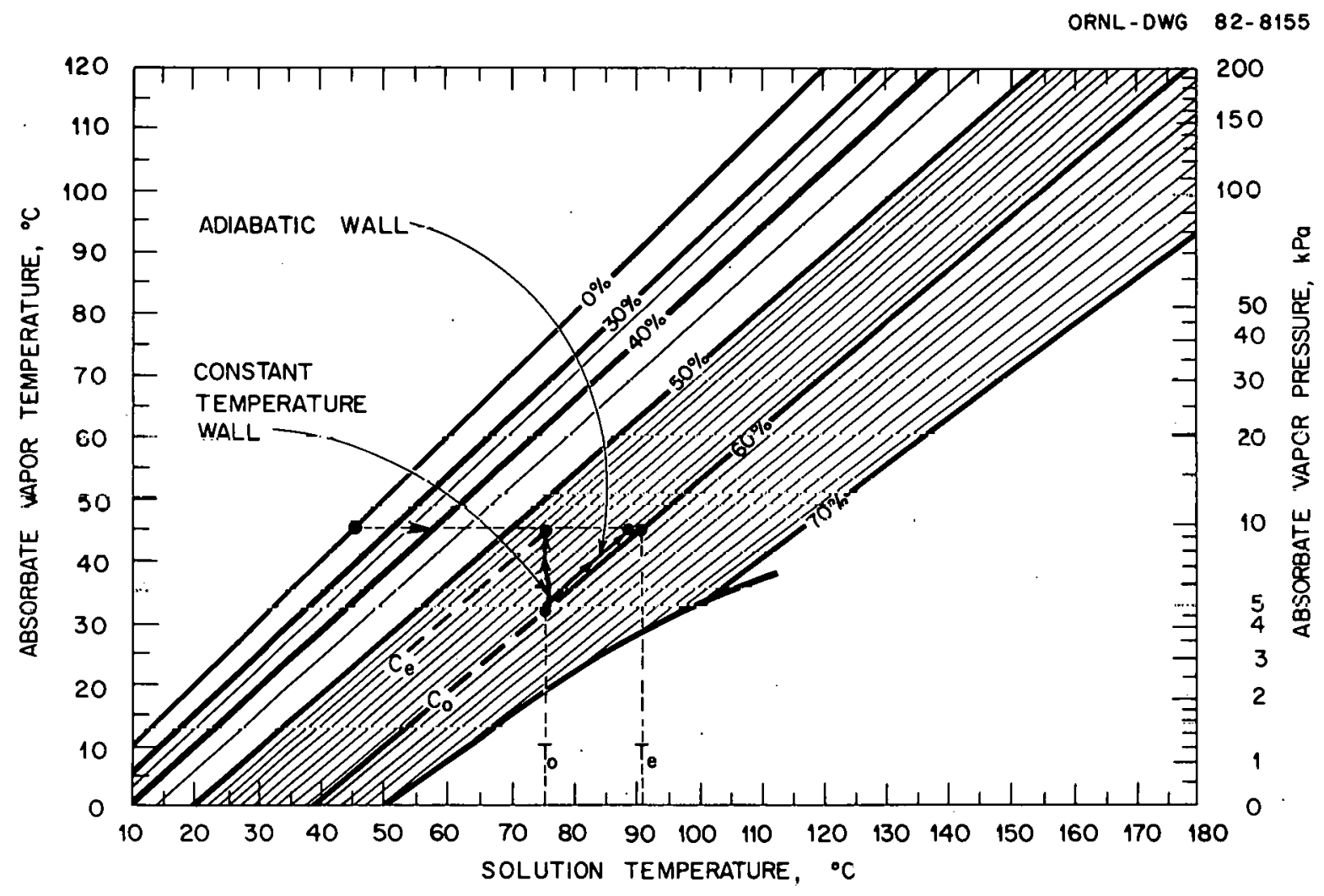

Fig. 15. Thermodynamic equilibrium chart for $\mathrm{LiBr}-\mathrm{H}_{2} \mathrm{O}$ solution, taken from ref. 19, illustrating the absorption process with an adiabatic wall and a constant-temperature wall, under the conditions of the numerical example.

$$
\begin{aligned}
& \Delta=\left(\frac{3 \mu \Gamma}{\rho^{2} \mathrm{~g} \sin \psi}\right)^{1 / 3}=\left(\frac{3 \times 3.0 \times 10^{-3} \times 0.25}{\left(1.72 \times 10^{3}\right)^{2} \times 9.8 \sin 45^{\circ}}\right)^{1 / 3}=0.48 \times 10^{-3} \mathrm{~m}, \\
& \mathrm{u}=\frac{\Gamma}{\rho \Delta}=\frac{0.25}{1.72 \times 10^{3} \times 0.48 \times 10^{-3}}=0.30 \mathrm{~m} / \mathrm{s} .
\end{aligned}
$$

Next, we find the equilibrium concentration and temperature $C_{e}$ and $\mathrm{T}_{e}$ used to calculate the normalized quantities $\gamma$ and $\theta$. Based on this definition, we find from the diagram, Fig. 15:

$$
C_{e}=52.8 \% \mathrm{LiBr}=47.2 \% \mathrm{H}_{2} \mathrm{O}=45.1 \frac{\mathrm{kmole} \mathrm{H}_{2} \mathrm{O}}{\mathrm{m}^{3} \text { solution }}
$$


Table 2. Physical properties of $\mathrm{LiBr}-\mathrm{H}_{2} \mathrm{O}$ solution at $60 \%$ concentration and $75^{\circ} \mathrm{C}^{\frac{2}{\mathrm{a}}}$

$\begin{array}{ll}\text { density, } \rho & 1.72 \times 10^{3} \mathrm{~kg} / \mathrm{m}^{3} \\ \text { dynamic viscosity, } \mu & 3.0 \times 10^{-3} \mathrm{~kg} / \mathrm{m} \cdot \mathrm{s} \\ \text { kinematic viscosity, } \nu=\mu / \rho & 1.74 \times 10^{-6} \mathrm{~m}^{2} / \mathrm{s} \\ \text { specific heat, } c_{p} & 0.92 \times 10^{3} \mathrm{~J} / \mathrm{kg} \cdot{ }^{\circ} \mathrm{C} \\ \text { thermal conductivity, } \mathrm{k} & 0.6 \mathrm{~W} / \mathrm{m} \cdot{ }^{\circ} \mathrm{C} \\ \text { thermal diffusivity, } \alpha=\mathrm{k} / \rho \mathrm{c} p & 0.38 \times 10^{-6} \mathrm{~m} / \mathrm{s} \\ \text { diffusion coefficient, } \mathrm{D} & 0.1 \times 10^{-8} \mathrm{~m} / \mathrm{s} \\ \text { Lewis number, Le }=\mathrm{D} / \alpha & 2.6 \times 10^{-3} \\ \text { heat of absorption, } \overline{\mathrm{H}} & 4.9 \times 10^{7} \mathrm{~J} / \mathrm{kmole}\end{array}$

$a_{\text {From refs. } 19 \text { and } 20 .}$

and $\mathrm{T}_{\mathrm{e}}=91.5^{\circ} \mathrm{C}$. We can now calculate the scaling parameters of the problem. The Lewis number, based solely on the properties of the solution, is listed in Table 2. The Peclet number is

$$
\mathrm{Pe}=\frac{\overline{\mathrm{u}} \Delta}{\alpha}=\frac{0.30 \times 0.48 \times 10^{-3}}{0.38 \times 10^{-6}}=379,
$$

and the dimensionless heat of absorption is

$$
\begin{aligned}
\lambda= & \text { Le } \frac{\bar{H} a\left(C_{e}-C_{o}\right)}{\rho C_{p}\left(T_{e}-T_{o}\right)}=2.6 \times 10^{-3} \times \frac{4.9 \times 10^{7}(45.1-38.2)}{1.72 \times 10^{3} \times 0.92 \times 10^{3}(91.5-75)} \\
& =3.37 \times 10^{-2} .
\end{aligned}
$$

We are now ready to use the results of the solution to answer the questions posed in the problem. For the adiabatic wall case, the asymptotic 
values of the normalized temperature and concentration, $\theta$ and $\gamma$, were found to be $\lambda /(\lambda+L e)$ and $L e /(\lambda+L e)$, respectively. Thus,

$$
\begin{aligned}
& \bar{\theta}_{\infty}=\frac{\lambda}{\lambda+\mathrm{Le}}=\frac{3.37 \times 10^{-2}}{3.37 \times 10^{-2}+2.6 \times 10^{-3}}=0.928=\frac{\overline{\mathrm{T}}_{\infty}-\mathrm{T}_{\mathrm{o}}}{\mathrm{T}_{\mathrm{e}}-\mathrm{T}_{\mathrm{o}}}, \\
& \overline{\mathrm{T}}_{\infty}=75+0.928(91.5-75)=90.3^{\circ} \mathrm{C}, \\
& \bar{\gamma}_{\infty}=\frac{\mathrm{Le}}{\lambda+\mathrm{Le}}=\frac{2.6 \times 10^{-3}}{3.37 \times 10^{-2}+2.6 \times 10^{-3}}=0.0716=\frac{\overline{\mathrm{C}}_{\infty}-\mathrm{C}_{\mathrm{o}}}{\mathrm{C}_{\mathrm{e}}-\mathrm{C}_{\mathrm{o}}}, \\
& \overline{\mathrm{C}}_{\infty}=38.2+0.0716(45.1-38.2)=38.7 \mathrm{kmole} \mathrm{H}_{2} 0 \text { per } \mathrm{m}^{3} \text { solution } \\
& =59.5 \% \mathrm{LiBr} .
\end{aligned}
$$

It is thus found that in adiabatic absorption the temperature of the solution increases from 75 to $90.3^{\circ} \mathrm{C}$, almost as high as the no-masstransfer limit of $91.5^{\circ} \mathrm{C}$. The concentration change is small, only from $60 \% \mathrm{LiBr}$ to $59.5 \% \mathrm{LiBr}$. However, in the constant-temperature wall case, the asymptotic value of $\gamma$ is unity, and, therefore, $C_{\infty}=C_{e}=52.8 \% \mathrm{LiBr}$.

It now remains to find the length of the tray required to produce $90 \%$ of the maximum concentration change: For the adiabatic wall case, we seek

$$
\bar{\gamma}=0.9 \bar{\gamma}_{\infty}=0.9 \times 0.0716=0.0644 \text {. }
$$

From a calculation similar to that leading to the plot in Fig. 3, for the values of $\lambda$ and Le at hand, we find that this occurs at $\zeta=30$. Thus,

$$
x=\zeta \operatorname{Pe} \Delta=30 \times 379 \times 0.48 \times 10^{-3}=5.46 \mathrm{~m}
$$

Similarly, for the constant-temperature wall case, we.seek $\gamma=0.9 \gamma_{\infty}=0.9$, which occurs at $\zeta=600$. Hence, the required $\mathrm{x}$ is $109 \mathrm{~m}$. It is thus clear that with laminar flow the length required to achieve full equilibrium is very large. This is not surprising in view of the 
low heat and mass transfer coefficients. However, if one is satisfied with partial equilibrium, the savings in the heat transfer area is considerable. 


\section{THIS PAGE}

\section{WAS INTENTIONALLY \\ LEFT BLANK}




\section{CONCLUSIONS}

A model was developed for analysis of the combined heat and mass transfer processes in absorption of vapor in laminar liquid films. The energy and diffusion equations were solved with an equilibrium boundary condition at the vapor-1iquid interface. Two cases of practical importance were considered: a constant-temperature wall and an adiabatic wall. Two methods of solution - analytical and numerical - were used with very good agreement between their respective results. In addition, an integral solution was developed which made it possible to obtain approximate analytical expressions for most parameters of interest. The solution was carried out for a linear absorbent, a mixture with a linear temperature-concentration equilibrium relation and a constant heat of absorption. The techniques of solution are suitable, however, for nonlinear absorbents with given characteristics.

The results of the solution describe the development of the thermal and concentration boundary layers and the variation of the temperatures, concentrations, and heat and mass fluxes. These quantities in their normalized, dimensionless forms depend on two characteristic parameters of the system: the Lewis number Le and the dimensionless heat of absorption $\lambda$. The length in the direction of flow is normalized with respect to the Peclet number and the film thickness. In the constanttemperature wall case, the dimensionless temperature and concentration reach asymptotic values of 0 and 1 , respectively. In the adiabatic wall case the asymptotic temperature and concentration are $\lambda /(\lambda+\mathrm{T}$.e $)$ and Le $/(\lambda+$ Le $)$, respectively.

Heat and mass transfer coefficients for the system were calculated. The Sherwood number for mass transfer from the vapor-liquid interface to the bulk of the film reaches an asymptotic value of 3.45 , with fully developed boundary layers for the constant-temperature wall. Lower value walls are obtained for an adiabatic wall. The Nusse1t number for heat transfer from the interface to the bulk reaches, under the same conditions, values of 4.23 and 2.65 for the adiabatic and constanttemperature walls, respectively. The Nusselt number for heat transfer from the bulk to the wall reaches 1.60 . 


\section{THIS PAGE}

\section{WAS INTENTIONALLY \\ LEFT BLANK}




\section{REFERENCES}

1. S. F. Chien and W. E. Ibele, "A Literature Survey: The Hydrodynamic Stability of the Liquid Film in Falling Film Flow and in Vertical, Annular, Two-Phase Flow," Int. J. Mech. Sci., 9, 547-57 (1967).

2. V. V. Vyazovov, "A Theory of Absorption of Slightly Soluble Gases by Liquid Films," J. Tech. Phys. (U.S.S.R.), 10, 1519-32 (1940).

3. W. E. Olbrich and J. D. Wild, "Diffusion from the Free Surface into a Liquid Film in Laminar Flow Over Defined Shapes," Chem. Eng. Sci., 24, 25-32 (1969).

4. Z. Rotem and J. E. Neilson, "Exact Solution for Diffusion to Flow Down an Incline," Can. J. Chem. Eng., 47, 341-46 (1969).

5. A. Tamir and Y. Taite1, "Diffusion to Flow Down an Incline with Surface Resistance," Chem. Eng. Sci., 26, 799-808 (1971).

6. V. V. Chavan and R. A. Maskelkar, "Gas Absorption in Falling NonNewtonian Films," Chem. Eng. J. Lauscone, 4, 223-28 (1972).

7. R. A. Mashelkar, V. V. Chavan, and N. G. Karanth, "Solution of the Problem of Gas Absorption in Falling Films of Non-Newtonian Fluids by Orthogonal Collocation Technique," Chem. Eng. J. Lausanne, 6, 75-77 (1973).

8. A. P. Lamourelle and 0. C. Sanda11, "Gas Absorption into a Turbulent Liquid," Chem. Eng. Sci., 27, 1035-43 (1972).

9. F. Kayihan and 0. C. Sanda11, "Gas Ahsorption with First Order Reaction in Turbulent Liquid Films," AIChE J., 20, 402-04 (1974).

10. F. Mendez and 0. C. Sanda11, "Gas Absorption Accompanied by Instantaneous B1molecular Reaction in Turbulent Liquids," AIChE J., $2.1,534-40$ (1975).

11. S. M. Yih and R. C. Seagrave, "Mass Transfer in Laminar Falling Liquid Films with Accompanying Heat Transfer and Interfacial Shear," Int. J. Heat Mass Transfer, 23, 749-58 (1980).

12. V. E. Nakoryakov and N. I. Giigor'eva, "Combined Heat and Mass Transfer During Absorption in Drops and Films," Inzh. Fiz. Zh., $32,399-405$ (1977).

13. N. I. Grigur'eva and V. E. Nakoryakov, "Exact Solution of Combined Heat and Mass Transfer Problem During Film Absorption," Inzh. F'iz. Zh., 33, 893-98 (1977). 
14. V. E. Nakoryakov and N. I. Grigor'eva, "Calculation of Heat and Mass Transfer in Non-Isothermal Absorption in the Entrance Region of a Falling Film," Tear. Osn. Khim. Tekhnol., 14, 483-88 (1980).

15. H. S. Harned and B. B. Owen, The Physical Chemistry of Electrolytic Solutions, Reinhold, New York, 1943.

16. E. M. Sparrow and E. C. Spalding, "Coupled Laminar Heat Transfer and Sublimation Mass Transfer in a Duct," J. Heat Transfer, 90, 115-24 (1968).

17. J. M. Ortega and W. G. Poole, An Introduction to Nromerical Methods for Differential Equations, Pitman Publishing, Marshfield, Mass., 257-62 (1981).

18. G. E. Forsythe, M. A. Malcolm, and C. B. Moler, Computer Methods for Mathematical Computations, Prentice Hall (1977).

19. ASHKAE Handbook and Product Directory, 1981 Fundamentals, Ámerican Society of Heating, Refrigeration, and Air-Conditioning Engineers, New York, 17.142 and 16.2, 1981.

20. International Critical Tables, McGraw Hill, New York (1929). 
The author is grateful to M. T. Heath, K. W. Childs, C. J. Emerson, and A. D. Solomon of the Computer Sciences Division for their assistance with the numerical calculations. 


\section{THIS PAGE \\ WAS INTENTIONALLY \\ LEFT BLANK}


INTERNAL DISTRIBUTION

\author{
1-5. H. G. Arnold \\ 6. V. D. Baxter \\ 7. R. S. Carlsmith \\ 8. F. C. Chen \\ 9. G. E. Courville \\ 10. F. A. Creswick \\ 11. S. G. DeCicco \\ 12. R. C. DeVault \\ 13. D. M. Eissenberg \\ 14. W. Fulkerson \\ 15. R. Eugene Goodson, Consultant \\ 16-20. G. Grossman \\ 21. V. O. Haynes \\ 22. H. W. Hoffman \\ 23. Todd R. LaPorte, Consultant \\ 24. C. G. Lawson \\ 25. L. N. McCold \\ 26. V. C. Mei
}

\author{
27-31. J. W. Miche1 \\ 32. Laurence I. Moss, Consultant \\ 33-37. E. A. Nephew \\ 38. F. S. Patton, Jr. \\ 39-43. H. Perez-Blanco \\ 44. C. K. Rice \\ 45-49. R. C. Robertson \\ 50. C. S. Robinson \\ 51. Milton Russel1, Consultant \\ 52. H. B. Shapira \\ 53. William H. Williams, Consultant \\ 54. A. J. Witten \\ 55-56. Laboratory Records Dept. \\ 57. Laboratory Records - RC \\ 58. ORNL Patent office \\ 59. Central Research Library \\ 60. Document Reference Section
}

EXTERNAL DISTRIBUTION

61. Ing. Jacob Agrest, Unigueletes 1100, Buenos Aires, Argentina

62. Prof. L. F. Albright, Chemical Engineering Dept., Purdue University, West Lafayette, IN 47907

63. Prof. G. Alefeld, Physik-Department der, TU München, D-8046 München-Garching, Federal Republic of Germany

64. R. A. Allen, Technical Supervisor, Buffalo Research Laboratory, Allied Chemical Corp., 20 Peabody Street, Buffalo, NY 14210

65. Redfield W. Allen, University of Maryland, Mechanical Engineering Dept., College Park, MD 20742

66. Dr. P. Anderson, Consultant, Arkla Industries, Inc., 9933 Crestview Place, Newburgh, IN 47630

67. Prof. Ing. H. D. Baehr, Institut für Thermodynamik, Universität Hannover, Callinstraße 36, 3000 Hannover 1, Federal Republic of Germany

68. Fred W. Bawel, Arkla Industries, Inc., $810 \mathrm{E}$. Franklin Street, P.0. Box 534, Evansville, IN 47701

69. Dr. J. Berghmans, Katholieke Universiteit Leuven, Institut Mechanica, Celestijnenlaan 300 A, B-3030 Heverlee-Belgium

70. Dr. Wendell Bierman, Carrier Corporation, Summit Landing, P.0. Box 4895, Syracuse, NY 13221

71. P. Blomberg, Electrolux, S-10545 Schweden, Sweden

72. Dr. Ulrich Bonne, Honeywe11 Corporate Technology Center, 10701 Lyndale Avenue, S., Bloomington, MN 55420 
73. Prof.'I. Borde, Research and Development Authority, Ben Gurion University of the Negev, P.0. Box 1025, Beer-Sheva 84110, Israel

74. Dr. Thomas E. Botts, Brookhaven National Laboratory, Upton, NY 11973

75. Joseph R. Bourne, P.0. Box 17144, Tucson, AZ 85731

76. Prof. R. Bugarel, Institut de Génie Chimique de Toulouse, Chemin de la Loge, Empalot, F-31078, Toulouse Cedex, France

77. James M. Calm, Electric Power Research Institute, 3412 Hillview, P.0. Box 10412, Palo Alto, CA 94303

78. E. C. Clark, Rocket Research Company, York Center, Redmond, WA 90852

79. Dr. H. M. Curran, Hittman Associates, Inc., 9190 Red Branch Road, Columbia, MD 21045

80. Dr. Ali Dabiri, Science Applications, Inc., P.0. Box 2351, LaJo11a, CA 92038

81. Dr. H. E. Davis, Concentration Specialists, Inc., 26 Dundee Park, Anduver, MA 01810

82. Dr. David Didion, National Bureau of Standards, B1dg. 226, Washington, D.C. 20234

83. Richard A. English, Carrier Corporation, P.0. Box 4808, Syracuse, NY 13221

84. Robert D. Fischer, Battelle Columbus Laboratories, 505 King Avenue, Columbus, OH 43201

85. J. H. Fraser, Concentration Specialists, Inc., 26 Dundee Park, Andover, MA 01810

86. Dr. Jack Goodman, Science Applications, Inc., 1257 Tasman Drive, Sunnyvale, CA 94806

87. Dr. E. Granryd, Dept. of Applied Thermodynamics and Refrigeration, Royal Institute of Technology, S-10044 Stockholm, Sweden

88. Dr. William T. Hanna, Battelle Columbus Laboratories, 505 King Avenue, Columbus, $\mathrm{OH} \quad 43201$

89. Dr. Floyd Hayes, Bldg. 12-G, The Trane Company, 3600 Thomas Creek Road, La Crosse, WI 54601

90. Dr. D. L. Ilodgett, Plant and Process Engineering Dept., BattelleInstitut e.V., Am Kömerhot 33, D-bUUU Frankfurt/M. 90, Federal Republic of Germany

91. Prof. J. Howell, Dept. of Mechanical Engineering, The University of Texas at Austin, Austin, TX 78712

92. Wallace Johnson, Concentration Specialists, Inc., 26 Dundee Park, Andover, MA 01810

93. P. Joyner, Vice President-Research, The Trane Company, 3600 Thomas Creek Road, La Crosse, WI 54601

94. Dr. H. Keller, Knapp Institute, Berlin, Federal Republic of Germany

95. Ing. G. A. Knobbout, TNO, Postbox 3 42, Apeldorn, Netherlands

96. Prot. Ing. K. F. Knoche, Lehrstuhl für Technische Thermodynamik, Rheinisch-Westfälische Hochschule, D-5100 Aachen, Federal Republic of Germany

97. Dr. Frank Kreith, Solar Energy Research Institute, 1617 Cole Blvd., Golden, Co 80401

98. Dip1:-Ing. P. Küppers, KFA Jülich, PLE, Postfach 1913, D-5170 Jülich 1, Federal Republic of Germany

99. Prof. Zalman Lavan, Dept. of Mechanical Engineering, Illinois Institute of Technology, Chicago, IL 60616

100. L. Ljung, AIB, Box 5511, S-11485 Stockholm, Sweden

101. Dr. Harold E. Loewer, Reinhold-Schneider, STR 135, 75 Karlsruhe 51, Germany 
103. Dr. Harold Lorsch, Franklin Research Center, Philadelphia, PA 19103

104. R. A. Macriss, Associate Director, Energy Conservation Research, Institute of Gas Technology, 4201 West 36th Street, Chicago, IL 60632

105. Ing. W. Malewski, Borsig GmbH, Berliner Straße 27-33, D-1000 Berlin 27, Federal Republic of Germany

106. Dr. D. J. Martin, ETSU, B1dg. 156, AERE Harwell, Oxfordshire OX 11 ORA, England

107. Lowell A. McNeely, 7310 Stenmeier Drive, Indianapolis, IN 46250

108. Richard Merrick, Arkla Industries, Inc., P.0. Box 534, Evansville, IN 47704

109. A. Mezzina, Brookhaven National Laboratory, Upton, NY 11973

110. Donald K. Miller, York Div. of Borg Warner Corp., Grantley Road, York, PA 17403

111. Prof. F. Moser, TU Graz, Kopernikusgasse 24, A-8010 Graz, Austria

112. Dip1. -Ing. V. Mucic, Energie- und Wasserwerke, Rhein-Nekar AG, Postface 2204, D-6800 Mannheim, Federal Republic of Germany

113. James W. Osborne, Department of Energy, CE-121, FORSTL, 1000 Independence Avenue, S.W., Washington, D.C. 20585

114. Dr. Amin Patani, Honeywel1 Corporate Technology Center, 10701 Lyndale Avenue, S., Bloomington, MN 55420

115. Dr. B. A. Phillips, Phillips Engineering Company, 721 Pleasant Street, St. Joseph, MI 49085

116. James M. Porter, The Trane Company, 3600 Pammell Creek Road, La Crosse, WI 54601

117. Dr. W. Raldow, Swedish Council for Building Research, Sankt Göransgatan 66, S-11233 Stockholm, Sweden

118. Dr. W. J. Rebello, Par Enterprises, Inc., 11928 Appling Valley Road, Fairfax, VA 22030

119. Dr. A. Rojey, Institut Francais du Pétrole, 14 Avenue de Bois - Préau, BP 311, F-92506 Rueil Malmaison Cedex, France

120. J. D. Ryan, Program Manager, Energy Conversion Equipment Branch, Dept. of Energy, CE-113.2, Room GH-068, 1000 Independence Avenue, S.W., Washington, D.C. 20585

121. J. M. Sallee, Gaz de France, Direction des Etudes et Techniques Nouvelles, 361 Avenue du Président Wilson, F-93211 La PlaineSt. Denis Cedex, France

122. Prof. Philip S. Schmidt, Dept. of Mechanical Engineering, The University of Texas at Austin, Austin, TX 78712

123. Prof. I. E. Smith, School of Mechanical Engineering, Cranfield Institute of Technology, Cranfield, Bedfordshire, England

124. Prof. Ing. F. Steimle, Institut für Angewandtr, Thermodynamik und Klimatechnik, Universität Essen, Universitätsstr. 15, D-4300 Essen, Foderal Republic of Germany

125. Prof. Ing. K. Stephan, Direktor des Instituts für Technische Thermndynamik. und Thermische Verfahrenstechnik, Universität Stuttgart, Pfaffenwaldring 9, D-7000 Stuttgart 80, Federal Republic of Germany

126. C. J. Swet, 7040 Woodvi.1.le Road, Mt. Airy, MD 21771

127. Prof. Ing. Ch. Trepp, Institut für Verfahrens- und Kältetechnik der Eidgenössischen, Technischen Hochschule Zürich, Switzerland

128. Prof. W. H. Tucker, Chemical Engineering Dept., Tri-State University, Angola, IN 46703

129. Prof. Gary C. V1iet, Dept. of Mechanical Engineering, The University of Texas at Austin, Austin, TX 78712 
130. Dr. Michael Wahlig, Lawrence Berkeley Laboratory, Berkeley, CA 94720

131. Prof. Ralph T. Webb, Dept. of Mechanical Engineering, Pennsylvania State University, University Park, PA 16802

132. M. Westermark, Scandiaconsult AB, Box 4560, S-10265, Stockholm, Sweden

133. Prof. G. Wettermark, Royal Institute of Technology, Division of Physical Chemistry, S-10044 Stockholm 70, Sweden

134. Eugene P. Whitlow, 1851 N. Valley View Drive, St. Joseph, MI 49085

135. W. Wilkinson, Energy and Thermal Engineering Section, Battelle Columbus Laboratories, 505 King Avenue, Columbus, $\mathrm{OH} 43201$

136. T. Zawacki, Institute of Gas Technology, 4201 West $36 \mathrm{th}$ Street, Chicago, IL 60632

137. Office of the Assistant Manager for Energy Research and Development, U.S. Department of Energy, Oak Ridge Operations, Oak Ridge, TN 37830

138-164. Technical Information Center, Department of Energy, P.0. Box 62, Oak Ridge, TN 37830 